OPEN ACCESS

Edited by:

Wenping Sun,

Zhejiang University, China

Reviewed by:

Zhong Jin,

Nanjing University, China

Wenhui Shi,

Zhejiang University of

Technology, China

*Correspondence:

Xifei Li

xfli2011@hotmail.com

Jianhong Peng

pjhhj@sohu.com

tThese authors have contributed equally to this work and share first authorship

Specialty section: This article was submitted to Electrochemistry,

a section of the journal

Frontiers in Chemistry

Received: 24 February 2020 Accepted: 03 April 2020

Published: 06 May 2020

Citation:

Huang Y, Xiong D, Li X, Maleki Kheimeh Sari H, Peng J, Li Y, Li Y, Li D, Sun Q and Sun X (2020) Recent Advances of Bimetallic Sulfide Anodes

for Sodium Ion Batteries.

Front. Chem. 8:353.

doi: 10.3389/fchem.2020.00353

\section{Recent Advances of Bimetallic Sulfide Anodes for Sodium Ion Batteries}

\author{
Yu Huang ${ }^{1 \dagger}$, Dongbin Xiong ${ }^{2 \dagger}$, Xifei Li $^{1,2,3 *}$, Hirbod Maleki Kheimeh Sari ${ }^{2}$, Jianhong Peng ${ }^{4 *}$, \\ Yingying $L i^{1}$, Yunyan $L^{1}{ }^{1}$, Dejun $L^{1}{ }^{1}$, Qian Sun ${ }^{5}$ and Xueliang Sun ${ }^{1,2,5}$
}

1 Tianjin International Joint Research Center of Surface Technology for Energy Storage Materials, College of Physics and Materials Science, Tianjin Normal University, Tianjin, China, ${ }^{2}$ Xi'an Key Laboratory of New Energy Materials and Devices, Institute of Advanced Electrochemical Energy \& School of Materials Science and Engineering, Xi'an University of Technology, Xi'an, China, ${ }^{3}$ State Center for International Cooperation on Designer Low-carbon \& Environmental Materials (CDLCEM), Zhengzhou University, Zhengzhou, China, ${ }^{4}$ School of Physical and Electronic Information Engineering, Qinghai Nationalities University, Xining, China, ${ }^{5}$ Department of Mechanical and Materials Engineering, University of Western Ontario, London, ON, Canada

The high usage for new energy has been promoting the next-generation energy storage systems (ESS). As promising alternatives to lithium ion batteries (LIBS), sodium ion batteries (SIBs) have caused extensive research interest owing to the high natural $\mathrm{Na}$ abundance of 2.4 wt.\% (vs. 0.0017 wt.\% for Li) in the earth's crust and the low cost of it. The development of high-performance electrode materials has been challenging due to the increase in the feasibility of SIBs technology. In the past years, bimetallic sulfides (BMSs) with high theoretical capacity and outstanding redox reversibility have shown great promise as high performance anode materials for SIBs. Herein, the recent advancements of BMSs as anode for SIBs are reported, and the electrochemical mechanism of these electrodes are systematically investigated. In addition, the current issues, challenges, and perspectives are highlighted to address the extensive understanding of the associated electrochemical process, aiming to provide an insightful outlook for possible directions of anode materials for SIBs.

Keywords: energy storage systems, lithium ion batteries, sodium ion batteries, bimetallic sulfides, anode materials

\section{INTRODUCTION}

In the past years, fossil fuels have been overexploited as the primary source of energy for industries and people's daily lives around the world. Simultaneously, risks of the resource shortage and the pollution of the environment due to the burning of fossil fuels have caused a development in the research and application of renewable energy sources. In the early 1990s, LIBs became an essential power supply in a variety of electronic devices since their first commercialization by Sony. With the increasing demand of clean energy, LIB has been one of the most indispensable energy storage technologies (Maleki Kheimeh Sari and Li, 2019; Su et al., 2020). However, the limited lithium resources and the high cost of Li have hampered the large-scale applications of LIBs. Therefore, it is of great importance to explore a new and novel candidate as an alternative for this type of batteries (Che et al., 2017; Hwang et al., 2017; Kang et al., 2017; Ortiz-Vitoriano et al., 2017; Xiao et al., 2017; Fan and Li, 2018). 
In recent years, SIBs have attracted much attention due to the similarities between $\mathrm{Na}$ and $\mathrm{Li}$ in terms of the chemical/electrochemical properties. Besides, sodium is the fourth most abundant metal element after aluminum, iron and calcium, which is evenly distributed in the earth's crust (Yu and Chen, 2020). Additionally, due to the abundant and cheap resources of $\mathrm{Na}$, SIBs were considered as one of the most promising candidates for large-scale renewable energy storage systems to store electricity from solar, wind and waves (Palomares et al., 2012; Kim et al., 2015; Kundu et al., 2015; Fan et al., 2016). However, there are still many differences between these two elements. As shown in Table 1, sodium has a larger ionic radius $(1.02 \AA)$ than that of $\operatorname{Li}(0.76 \AA)$ which is heavier than an atom, and also a higher standard electrode potential (Slater et al., 2013; Chen J. et al., 2017; Meng, 2017; Xiao et al., 2017; Fang Y. et al., 2018; Wang et al., 2018). Although SIBs are inferior to LIBs in terms of energy density and charge-discharge rate, $\mathrm{Li}$ and $\mathrm{Na}$ are just a fraction of the whole electrode, and the capacity is largely depended on the characteristics of the active materials. Therefore, exploring exceptional properties anodes for advanced SIBs is the key point in developing this technology, which is indeed accompanied with many challenges (Li and Wang, 2012; Cao et al., 2017; Lin et al., 2018; Xiong et al., 2018). In general, a well-designed nanostructure materials can shorten ion diffusion paths and electron, routes, and mitigate the mechanical stress caused by large volume expansion. Additionally, comparing to the carbon-based anode materials (e.g., porous carbon, nitrogendoped carbon nanofibers) (Lai et al., 2012; Kong et al., 2014; Xiao et al., 2014, 2017), metallic compound materials possess a higher theoretical specific capacity due to their excellent electrochemical conversion mechanism (Yang et al., 2015; Yu et al., 2015; Chen Y. et al., 2016; Wu et al., 2016; Yu X-Y. et al., 2016; Wen et al., 2017). For example, many mono-layered transition metal oxides $\left(\mathrm{MOs}-\mathrm{NiO}_{2}, \mathrm{FeO}_{2}, \mathrm{TiO}_{2}, \mathrm{MnO}_{2}\right.$, and etc Xia et al., 2014; Yu D. J. et al., 2016) have been extensively studied as $\mathrm{Na}$ storage materials. $\mathrm{NiO}_{2}$ exhibited a reversible capacity of about $123 \mathrm{mAh} \mathrm{g}^{-1}$ with a small polarization. Monolayered $\mathrm{FeO}_{2}$ showed the largest reversible capacity (up to 80 $\mathrm{mAh} \mathrm{g}^{-1}$ ) at a high cut-off voltage of $3.5 \mathrm{~V}$. When used as electrode material in $\mathrm{SIBs}_{2} \mathrm{TiO}_{2}$ also showed an excellent capacity retention (25\% capacity fading over 1,200 cycles). Indeed, $\mathrm{MnO}_{2}$ was synthesized by a simple redox reaction and hydrothermal treatment method, and a large discharge capacity of $219 \mathrm{mAh}$ $\mathrm{g}^{-1}$ was delivered. Jiang et al. developed a $\mathrm{Fe}_{2} \mathrm{O}_{3}$ thin film as an anode for SIBs with a steady capacity of $380 \mathrm{mAh} \mathrm{g}^{-1}$ after 200 cycles. However, metallic oxides (MOs) have several disadvantages derived from their low electroconductibility and electrochemical activity (Du et al., 2015; Zhu et al., 2015; Yu and David Lou, 2018).

Among various anode materials reported for SIBs, metallic sulfides (MSs) have drawn much attention due to their reversibility of redox reactions, excellent capacity and faster conductivity compared to MOs. M-S bond in MSs is weaker than homologous $\mathrm{M}-\mathrm{O}$ bond in $\mathrm{MOs}$ due to the different electronegativity of $\mathrm{S}$ and $\mathrm{O}$, facilitating chemical reactions during the charge-discharge ( $\mathrm{Li}$ et al., 2015; Yu X-Y. et al., 2016; Zheng et al., 2017). For example, $\mathrm{MoS}_{2}$ nanosheets as
TABLE 1 | Comparison of $\mathrm{Li}$ and $\mathrm{Na}$.

\begin{tabular}{lll}
\hline & Li & Na \\
\hline lonic radius & $0.76 \AA$ & $1.02 \AA$ \\
Content in the earth's crust/Reserve & $0.0065 \% / 1350 \mathrm{~W} \mathrm{t}$ & $2.4 \% / 500,000 \mathrm{Wt}$ \\
Cost of trona (per ton) & $\$ 5,000$ & $\$ 135-165$ \\
Weight & $7 \mathrm{~g} \mathrm{~mol}^{-1}$ & $23 \mathrm{~g} \mathrm{~mol}^{-1}$ \\
Standard electrode potential (vs. SHE) & $-3.02 \mathrm{~V}$ & $-2.71 \mathrm{~V}$ \\
\hline
\end{tabular}

anode material in SIBs showed a good charge-discharge capacity of $386 \mathrm{mAh} \mathrm{g}^{-1}$. However, MSs suffer from severe problems such as volume expansion during the $\mathrm{Na}^{+}$insertion/extraction process, sluggish $\mathrm{Na}^{+}$diffusion kinetics, and poor electrical conductivity, which may result in some defects accompanied by capacity fading, poor cycle life, and unacceptable rate performance. Many researches have been known to enhance the electrochemical performance of these anode materials through reasonable structural design (Zhou Q. et al., 2016; Hwang et al., 2017).

Along with MSs, BMSs have also become a hot topic as SIBs anode materials regarding their high electronic conductivity, good electrochemical activity, and strong electrochemical controllability (Li et al., 2013; Youn et al., 2016; Li Y. et al., 2017; Tang et al., 2017). Thus far, BMSs with different morphologies and structures, (e.g., nanosheets, nanoplates, nanotubes, ballin-ball hollow spheres, nanopetals, and urchin-like structures) have been reported as high performance anodes in LIBs (Chen T. et al., 2016; Li et al., 2016; Ma et al., 2016). Up to now, there are quite a number of remarkable works in regards to the application of BMSs as anode materials in LIBs. The synergistic effect between BMSs with higher theoretical capacity and optimized nanostructure can more effectively maintain the mechanical stability compared with MOs and MSs (Lai et al., 2012; Kong et al., 2014; Chen Y. et al., 2016; Wu et al., 2016). One example is 0D/1D C@FeCo-S NDS/CNR composite prepared through hydrothermal method (Gao et al., 2017), or yolk-shell-structured Fe-Ni-S powders and $\left(\mathrm{Ni}_{0.3} \mathrm{Co}_{0.7}\right)_{9} \mathrm{~S}_{8} / \mathrm{N}-\mathrm{CNTs} / \mathrm{rGO}$ composite with ultrahigh long-life cycling stability and outstanding rate property as an anode for SIBs. The reason may be owing to their smaller volume change and higher initial coulombic efficiency (ICE), yielding a low irreversible capacity (Kim and Kang, 2017). Li and his co-workers prepared $\mathrm{NiCo}_{2} \mathrm{~S}_{4}$ with $\mathrm{N}$-doped carbon served as an anode material for SIBs through a bottom-up strategy, and by adjusting optimal voltage region an outstanding capacity of $570 \mathrm{mAh} \mathrm{g}^{-1}$ over 200 cycles at $0.2 \mathrm{~A} \mathrm{~g}^{-1}$ was obtained (Li S. et al., 2019).

Moreover, BMSs possess higher electronic conductivity and more abundant redox reactions than single MSs, which can dramatically strengthen the electrochemical performances. However, there are only a few reviews concentrated on BMS-based anodes for SIBs (Yan et al., 2014; Fan et al., 2016; Chang et al., 2017). The recent progresses of BMS anode in SIBs, the various synthesis strategies, and their sodium storage mechanisms along 
with their limitations are systematically discussed in this review. In the end, the existing challenges and opportunities for designing high-performance BMS anodes for SIBs are introduced.

\section{SODIUM STORAGE MECHANISM}

Owing to the high theoretical specific capacity and low cost, BMSs have been a propitious class of anode materials for both LIBs and SIBs (Duan et al., 2019). When used in SIBs, BMSs can reserve $\mathrm{Na}^{+}$via special mechanism. In some cases, an intercalation/de-intercalation process or an alloy-dealloying reaction happens in the process of charge-discharge, which is depended on BMSs (Li Z. et al., 2017; Yan et al., 2017).

Generally, in the first discharge process of BMSs (e.g., $\mathrm{NiCo}_{2} \mathrm{~S}_{4}$ (Zhang et al., 2018), $\mathrm{CuCo}_{2} \mathrm{~S}_{4}$ (Gong et al., 2018; Li Q. et al., 2019), $\mathrm{Ti}_{0.25} \mathrm{Sn}_{0.75} \mathrm{~S}_{2}$ (Huang et al., 2018), and $\mathrm{ZnSnS}_{3}$ Jia et al., 2018; Liu et al., 2019), $\mathrm{Na}^{+}$intercalates into BMSs and then a reversible conversion reaction occurs (Li S. et al., 2019). The principle of correlation reaction is similar to that of LIBs. Nonetheless there are some distinctions in the reaction process between SIBs and LIBs (Stephenson et al., 2014; Zhang et al., 2014). The first reduction process is attributed to $\mathrm{Na}^{+}$intercalation in BMSs without any phase transformation, Equation (1). In the same cycle the conversion reactions occur, as summarized in Equations (2) and (3), which provide an impressive capacity cause structural instability (Jin et al., 2015; Song et al., 2017; Li S. et al., 2019).

$$
\begin{aligned}
& \mathrm{MS}_{\mathrm{x}}+\mathrm{xNa}^{+}+\mathrm{xe}^{-} \rightarrow \mathrm{Na}_{\mathrm{x}} \mathrm{MS}_{\mathrm{x}} \\
& \mathrm{Na}_{\mathrm{x}} \mathrm{MS}_{\mathrm{x}}+(2-\mathrm{x}) \mathrm{Na}^{+}+(2-\mathrm{x}) \mathrm{e}^{-} \rightarrow \mathrm{MS}+\mathrm{Na}_{2} \mathrm{~S} \\
& \mathrm{MS}+2 \mathrm{Na}^{+}+2 \mathrm{e}^{-} \rightarrow \mathrm{M}+\mathrm{Na}_{2} \mathrm{~S}
\end{aligned}
$$

As another kind of $\mathrm{Na}$ storage mechanism, $\mathrm{ZnSnS}_{3}$ is used as an anode for SIBs, $\mathrm{Na}^{+}$intercalates into the layered structure in the initial sodiation process. During the whole electrochemical process, a combined conversion mechanism and alloy-dealloying mechanism occurs. The corresponding reaction can be depicted as follows (e.g., $\mathrm{ZnSnS}_{3}$ ): (Fu et al., 2015; Qin et al., 2016b; Dong et al., 2017; Deng et al., 2018; Zhang Y. et al., 2019).

$$
\begin{aligned}
\text { Conversion reaction : } & \mathrm{ZnSnS}_{3}+6 \mathrm{Na}^{+}+6 \mathrm{e}^{-} \\
& \rightarrow \mathrm{Sn}+\mathrm{Zn}+3 \mathrm{Na}_{2} \mathrm{~S} \\
\text { Alloying reaction }: 4 \mathrm{Sn}+ & 13 \mathrm{Zn}+16 \mathrm{Na}^{+}+16 \mathrm{e}^{-} \\
\rightarrow & \mathrm{Na}_{15} \mathrm{Sn}_{4}+\mathrm{NaZn}_{13}
\end{aligned}
$$

It is important noting that during the electrochemical process of BMS electrodes ( $\mathrm{M}=\mathrm{Zn}$, Co) conversion reactions are bound to happen and the following reaction equations can be speculated, $\mathrm{NiCo}_{2} \mathrm{~S}_{4}$ can be used as an example, while $\mathrm{Na}_{\mathrm{x}} \mathrm{MS}_{\mathrm{y}}$ is the intermediate product of the intercalation reaction:

$$
\begin{aligned}
\text { Discharge }: \mathrm{MS}_{\mathrm{x}}+\mathrm{xNa}^{+}+\mathrm{xe}^{-} \rightarrow \mathrm{Na}_{\mathrm{x}} \mathrm{MS}_{\mathrm{x}}(\mathrm{M}=\mathrm{Ni} / \mathrm{Co}) \\
3.0-1.3 \mathrm{~V} \\
\mathrm{Na}_{\mathrm{x}} \mathrm{MS}_{\mathrm{x}}+(2-\mathrm{x}) \mathrm{Na}^{+}+(2-\mathrm{x}) \mathrm{e}^{-} \rightarrow \mathrm{MS}+\mathrm{Na}_{2} \mathrm{~S} \\
1.3-0.6 \mathrm{~V} \\
\mathrm{MS}+2 \mathrm{Na}^{+}+2 \mathrm{e}^{-} \rightarrow \mathrm{M}+\mathrm{Na}_{2} \mathrm{~S} \\
0.6-0.1 \mathrm{~V} \\
\mathrm{NiCo}_{2} \mathrm{~S}_{4}+8 \mathrm{Na}^{+}+8 \mathrm{e}^{-} \rightarrow 4 \mathrm{Na}_{2} \mathrm{~S}+\mathrm{Ni}+2 \mathrm{Co} \\
3.0-0.1 \mathrm{~V} \\
\mathrm{Charge}_{\mathrm{Ni}}+\mathrm{Na}_{2} \mathrm{~S} \rightarrow \mathrm{NiS}_{\mathrm{x}}+2 \mathrm{Na} \\
0.1-0.7 \mathrm{~V} \\
\mathrm{Co}+\mathrm{Na}_{2} \mathrm{~S} \rightarrow \mathrm{CoS}_{\mathrm{x}}+2 \mathrm{Na} \\
1.7-3.0 \mathrm{~V} \\
2 \mathrm{Na}_{2} \mathrm{~S}+\mathrm{Ni}+\mathrm{Co} \rightarrow \mathrm{NiS}_{\mathrm{x}}+\mathrm{CoS}_{\mathrm{x}}+4 \mathrm{Na} \\
0.1-3.0 \mathrm{~V}
\end{aligned}
$$

\section{SYNTHESIS OF BMS WITH NANOSTRUCTURES}

\section{Solvothermal Methods}

As a low-cost and environmentally friendly synthetic method, solvothermal reaction is effective to synthesize various nanomaterials with disparate morphologies, complete crystal particles, small particle sizes, uniform distribution, controllable stoichiometry, and high crystallinity. Due to the above merits, the solvothermal method has been widely employed in synthesizing new structures and materials. In the past decades, this method has been frequently used in preparing oxide-based and S-based materials with ideal structure and controllable size for SIBs. Over recent years, BMSs with various morphologies have been successfully synthesized via solvothermal method. For example, $\mathrm{NiCo}_{2} \mathrm{~S}_{4}$ nanodots with $\mathrm{N}$-doped carbon $\left(\mathrm{NiCo}_{2} \mathrm{~S}_{4} @ \mathrm{NC}\right)$ (Li S. et al., 2019), $\mathrm{NiCo}_{2} \mathrm{~S}_{4}$ hollow prism wrapped in reduced graphene oxide (rGO) (Zhang et al., 2018), N/S-rGO@ZnSnS 3 amorphous $\mathrm{ZnSnS}_{3} @ \mathrm{rGO}$ (Liu et al., 2019), (( $\left.\left.\mathrm{Ni}_{0.3} \mathrm{Co}_{0.7}\right)_{9} \mathrm{~S}_{8} / \mathrm{N}-\mathrm{CNTs} / \mathrm{rGO}\right)$ (Lv et al., 2018), $\left(\mathrm{Co}_{0.5} \mathrm{Ni}_{0.5}\right)_{9} \mathrm{~S}_{8} / \mathrm{N}-\mathrm{C}$ ) nanoparticles (Cao et al. 2019), $\mathrm{CuCo}_{2} \mathrm{~S}_{4} / \mathrm{rGO}$ nanoparticles (Li Q. et al., 2019), and so forth. These nanostructured materials synthesized through solvothermal method possess strong controllability, excellent electrochemical performance, fast ions, and electron transfer paths and outstanding rate capability (Zhao and Manthiram, 2015; Liu et al., 2017; Jia et al., 2018; Chen et al., 2019).

A new type of hierarchical $\mathrm{rGO}$ wrapped $\mathrm{NiCo}_{2} \mathrm{~S}_{4}$ composite was synthesized through refluxing and solvothermal reactions by Yin's group. As shown in Figures 1A-C, SEM images indicate that $\mathrm{NiCo}_{2} \mathrm{~S}_{4}$ nanoprisms with a uniform size are tightly absorbed onto the negatively charged graphene oxide nanosheets because of the electrostatic interactions between them (Zhang et al., 2018). $\left(\mathrm{Ni}_{0.3} \mathrm{Co}_{0.7}\right)_{9} \mathrm{~S}_{8} / \mathrm{N}-$ $\mathrm{CNTs} / \mathrm{rGO}$ nanoparticles were also obtained through a tightly in-situ growth onto rGO, as shown in Figure 1D (Lv et al., 2018). Chen et al. synthesized the lantern-like architecture $\mathrm{Ti}_{0.25} \mathrm{Sn}_{0.75} \mathrm{~S}_{2}$ with MWCNTs composite through 
A

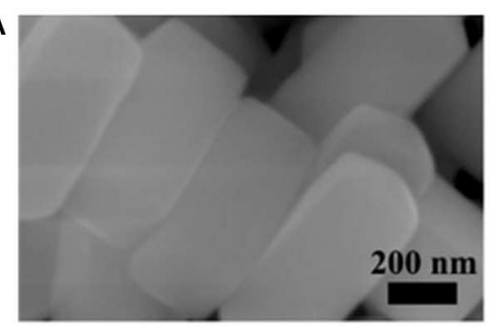

B

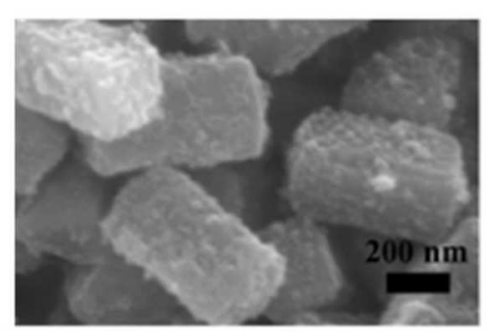

C

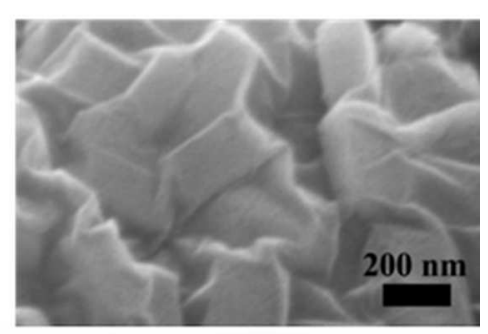

D

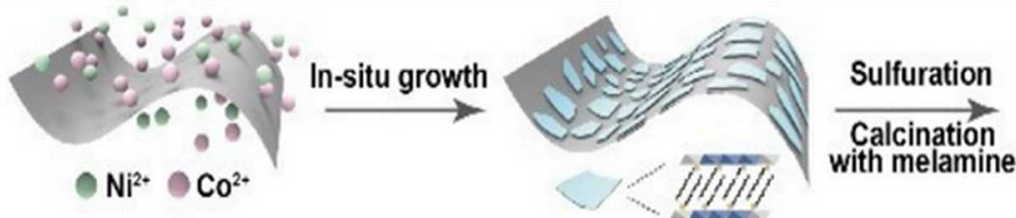

E

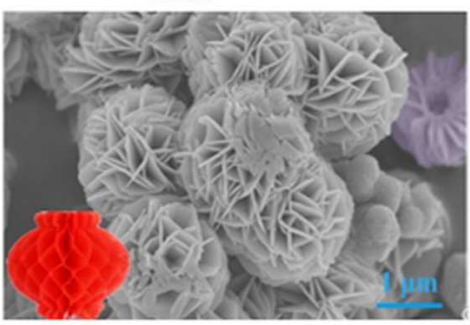

NiCo-LDH/rGO Precursor

G
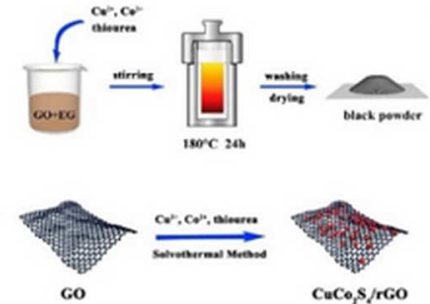

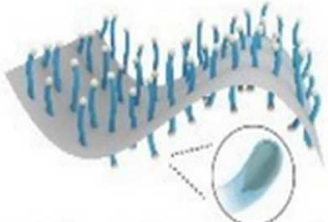

\section{$\left(\mathrm{Ni}_{0.3} \mathrm{CO}_{0.7}\right)_{9} \mathrm{~S}_{8} / \mathrm{N}-\mathrm{CNT} / \mathrm{rGO}$}

H

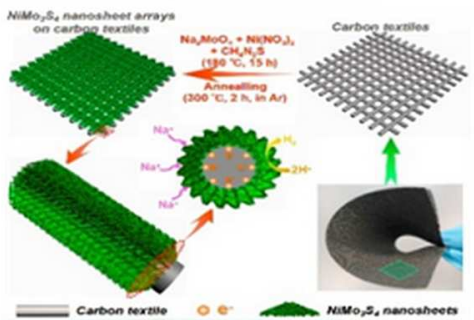

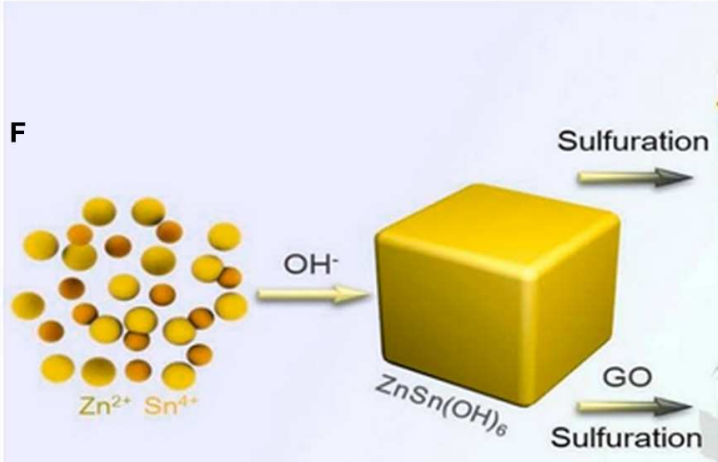

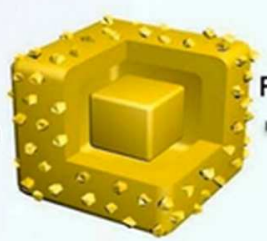

Ripening

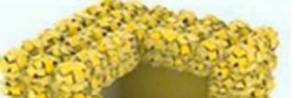

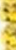
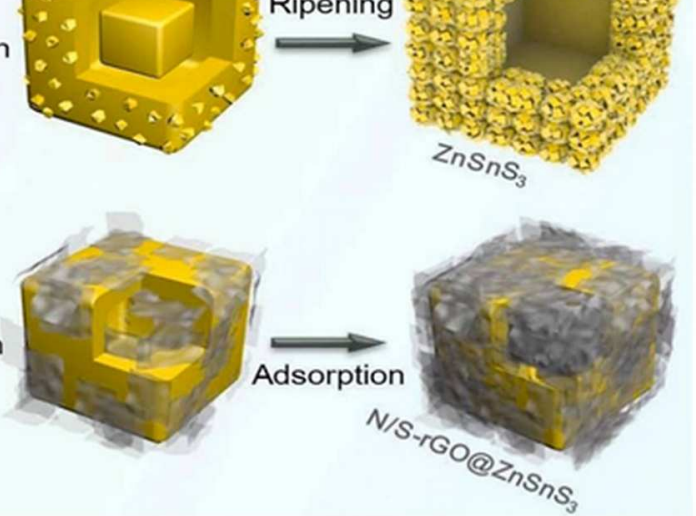

FIGURE 1 | (A-C) SEM images of the NiCo precursor, $\mathrm{NiCO}_{2} \mathrm{~S}_{4}$ and $\mathrm{rGO}-\mathrm{NiCO}_{2} \mathrm{~S}_{4}$, respectively. Reproduced with permission from Zhang et al. (2018) Copyright 2018, Royal Society of Chemistry. (D) Schematic illustration of preparing $\left(\mathrm{Ni}_{0.3} \mathrm{Co}_{0.7}\right)_{9} \mathrm{~S}_{8} / \mathrm{N}$-CNTs/rGO. Reproduced with permission from Lv et al. (2018) Copyright 2018, Royal Society of Chemistry. (E) SEM images of the lantern-like Ti $0_{0.25} \mathrm{Sn}_{0.75} \mathrm{~S}_{2}$ micro-particles. Reproduced with permission from Huang et al. (2018) Copyright 2018, Elsevier. (F) Schematic illustration for the preparation process of $\mathrm{ZnSnS}_{3}$ and N/S-rGO@ZnSnS 3 . Reproduced with permission from Liu et al. (2019) Copyright 2019, Elsevier. (G) Schematic illustration for the formation of $\mathrm{CuCo}_{2} \mathrm{~S}_{4} / \mathrm{rGO}$. Reproduced with permission from Gong et al. (2018) Copyright 2018, Elsevier.

(H) Schematic illustration for the synthesis of $3 \mathrm{D}$ hierarchical $\mathrm{NiMo}_{3} \mathrm{~S}_{4}$ nanosheet arrays on the flexible carbon textiles. Reproduced with permission from Kong et al. (2018) Copyright 2018, Elsevier.

the hydrothermal method (Figure 1E) (Huang et al., 2018). Particularly, the unique architecture with abundant pores and large surface area can not only shorten the transmission path of $\mathrm{Na}^{+}$, but also reserve a large space for volume expansion. Liu's group, for the first time, designed hollow $\mathrm{ZnSnS}_{3}$ nano-microcubes with a N/S dual-doped rGO encapsulated (donated as N/S-rGO@ZnSnS 3 ). During the preparation process, the precursor of $\mathrm{ZnSn}(\mathrm{OH})_{6}$ cubes have been successfully synthesized through an easy co-precipitation method. Afterwards, the precursor was mixed with $\mathrm{Na}_{2} \mathrm{~S}$, thiourea and GO dispersion, and finally the N/S-rGO@ZnSnS 3 material was obtained through a typical hydrothermal reaction (Figure 1F) (Liu et al., 2019). The above-mentioned experiments were all following a two-step method. Nonetheless, recently, $\mathrm{CuCo}_{2} \mathrm{~S}_{4} / \mathrm{rGO}$ nanocomposites was prepared through onestep solvothermal method by Zhao's group, as illustrated schematically in Figure 1G (Gong et al., 2018). Yang et al. also synthesized a bind-free SIBs anode material with 
hierarchical hybrid nanostructure which consisted of $\mathrm{NiMo}_{3} \mathrm{~S}_{4}$ nanosheet arrays grown on flexible carbon textiles (denoted as $\mathrm{NiMo}_{3} \mathrm{~S}_{4} / \mathrm{CTs}$ ) through a one-step hydrothermal method and subsequent post-annealing process (Figure 1H) (Kong et al., 2018).

Moreover, $\mathrm{VMo}_{2} \mathrm{~S}_{4}$-rGO nanosheets (Zhang $\mathrm{K}$. et al., 2019), ZnSnS $3 @$ @GO nanoparticles (Jia et al., 2018), $\mathrm{Cu}_{2} \mathrm{MoS}_{4}$ nanoparticles (Chen et al., 2019), $\mathrm{CuCo}_{2} \mathrm{~S}_{4}$ sub-microspheres (Li
Q. et al., 2019), and $\operatorname{CoSnS}_{\mathrm{x}} @ \mathrm{NC}$ nanoboxes (Liu et al., 2017) have been successfully prepared using a similar approach.

\section{Spray Pyrolysis}

Spray pyrolysis is a popular method for preparing BMSs with small particle size and good dispersion. Indeed, spray pyrolysis is a processing technique being considered in many researches to prepare thin and thick films, ceramic coatings, and powders.
A

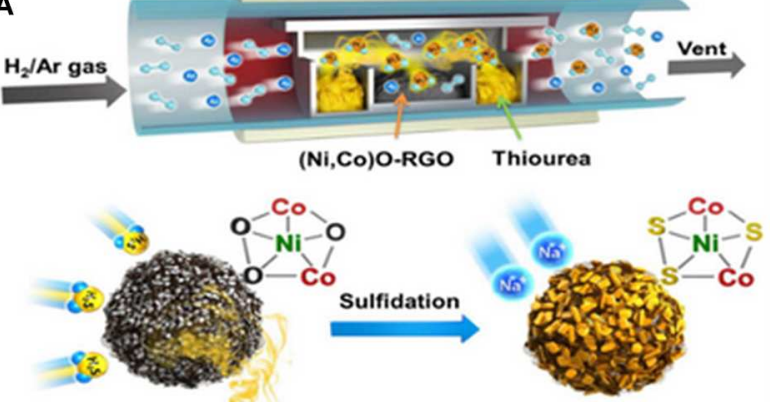

(Ni,Co)O-RGO powder

$\mathrm{Ni}_{3} \mathrm{Co}_{6} \mathrm{~S}_{4}-\mathrm{RGO}$ powder
C

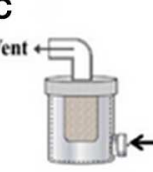

Bag filter
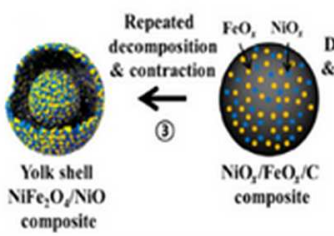

E

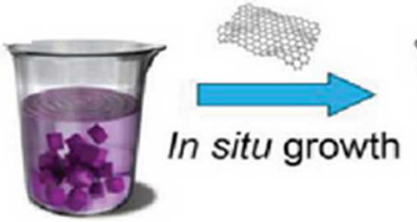

$\sqrt{ }$ Co-precipitation

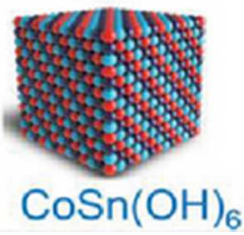

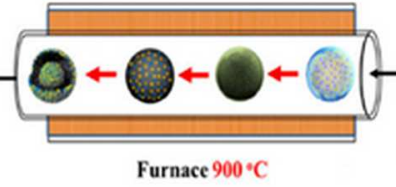

Decomposition

$\leftarrow$

$$
\text { Metal salts/sucrose }
$$
composite
B

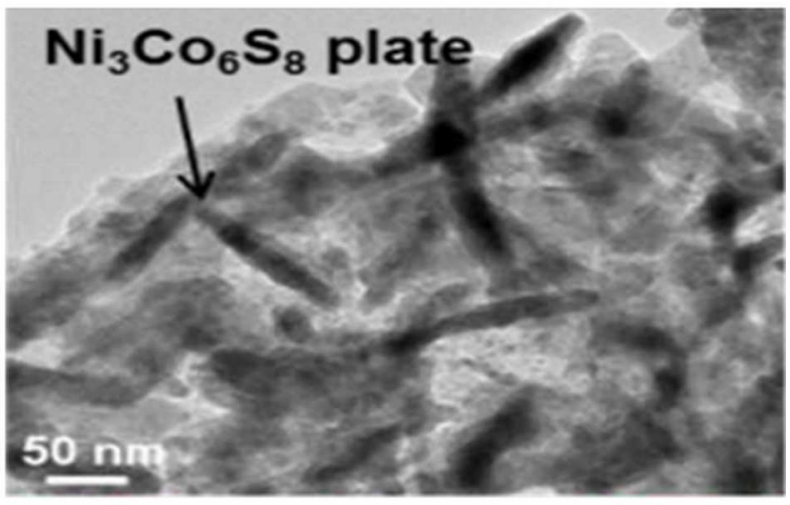

D

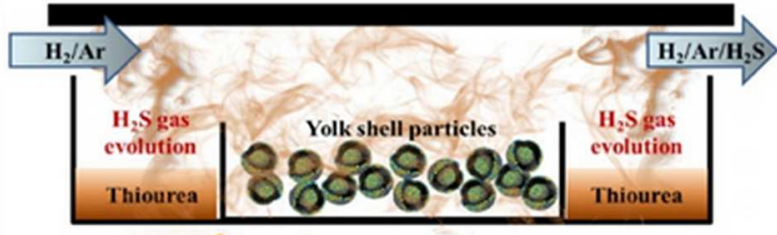

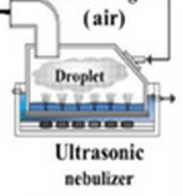
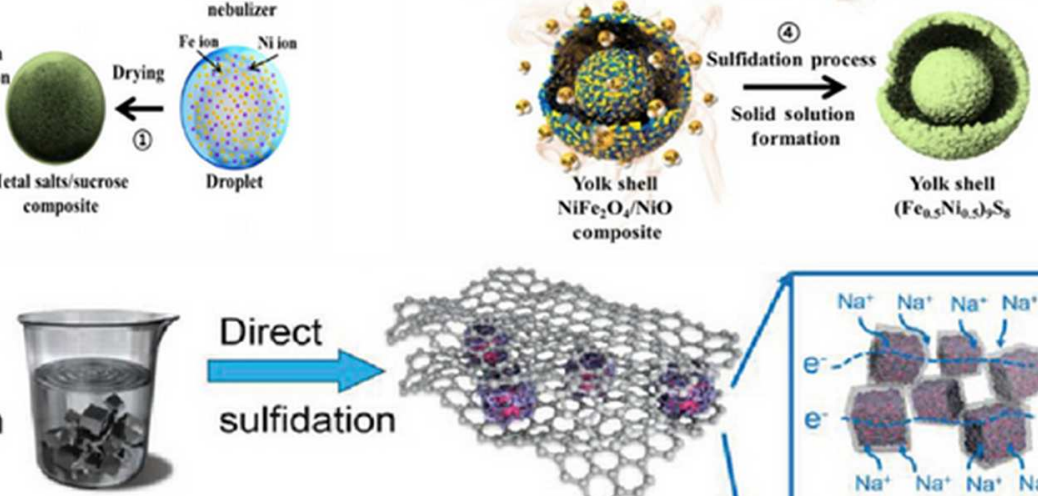

Direct sulfidation
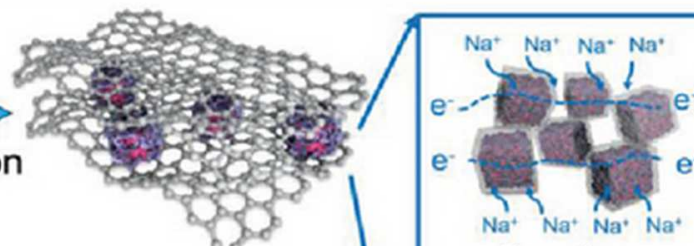

Overview
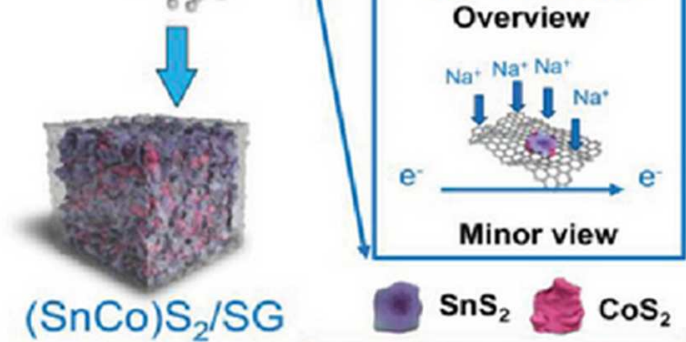

FIGURE 2 | (A) Schematic illustration for the formation mechanism of the $\mathrm{Ni}_{3} \mathrm{Co}_{6} \mathrm{~S}_{8}-\mathrm{rGO}$ powder. (B) TEM image of the $\mathrm{Ni}_{3} \mathrm{Co}_{6} \mathrm{~S}_{8}$-rGO composite powder. Reproduced with permission from Choi and Kang (2015a) Copyright 2015. Royal Society of Chemistry. (C) Schematic diagrams for the preparation of the carbon-free Fe-Ni-O powders (D) the sulfidation process. Reproduced with permission (Kim and Kang, 2017) Copyright 2017, Tsinghua University Press. (E) Schematic illustration for the synthesis of (SnCo)S 2 SG. Reproduced with permission from Yang et al. (2019) Copyright 2019. Wiley-VCH. 
It offers an extremely easy approach for preparing samples of any composition. Compared with other deposition techniques, spray pyrolysis presents a very simple and relatively low-cost processing way.

For instance, a hollow $\mathrm{Ni}_{3} \mathrm{Co}_{6} \mathrm{~S}_{8}-\mathrm{rGO}$ sphere with plateshape nanocrystals of nickel-cobalt sulfide $\left(\mathrm{Ni}_{3} \mathrm{Co}_{6} \mathrm{~S}_{8}\right)$ uniformly distributed on a crumpled rGO structure (Figure 2A) via spray pyrolysis was prepared as an anode for SIBs. The small $\mathrm{Ni}_{3} \mathrm{Co}_{6} \mathrm{~S}_{8}$ plate-shape nanocrystals were embedded in $\mathrm{rGO}$, resulting in a 3D hollow interconnected nanocomposite (Figure 2B) (Choi and Kang, 2015a). In addition, a yolk-shell-structured $\left(\mathrm{Fe}_{0.5} \mathrm{Ni}_{0.5}\right)_{9} \mathrm{~S}_{8}$ solid-solution powder was prepared by the same group via a onepot spray pyrolysis process as anode for SIBs. As a result, an excellent electrochemical performance was achieved. Schematic diagrams of the preparation process are shown in Figures 2C,D (Kim and Kang, 2017).

The primary advantage of this method is that BMS electrode materials could be synthesized in only one step, and without any further treatments.

\section{Co-precipitation Method}

The co-precipitation method has been used in recent years for preparing homodisperse BMSs nanostructure materials in SIBs. This method is proved to possess prominent virtues, such as easily obtaining nanomaterials with high phase purity, and preparing nano-powder with controllable particle size and uniform distribution.

By employing the co-precipitation method, Yang et al. reported a kind of $(\mathrm{SnCo}) \mathrm{S}_{2} / \mathrm{rGO}$ nanocubes (Figure 2E) (Yang et al., 2019). In addition, $\mathrm{Ou}$ and his co-workers synthesized $\mathrm{MnSn}(\mathrm{OH})_{6}$ nanoboxes firstly through a straightforward co-precipitation process, then $\mathrm{SnS}_{2} / \mathrm{Mn}_{2} \mathrm{SnS}_{4} / \mathrm{C}$ nanoboxes (SMS/C) were prepared through the facial wet-chemical method. As an anode material for SIBs, the SMS/C electrode can show a high ICE of $90.8 \%$, excellent rate capability $\left(488.7 \mathrm{mAh} \mathrm{g}^{-1}\right.$ at $10 \mathrm{~A} \mathrm{~g}^{-1}$ ) and long cycling stability (522.5 $\mathrm{mAh} \mathrm{g}^{-1}$ at $5 \mathrm{~A} \mathrm{~g}^{-1}$ was retained after 500 cycles) (Ou et al., 2019).

Due to its advantages, an easy operation, low cost, and less synthesis time, the co-precipitation method has been broadly utilized to prepare BMSs as anode materials for SIBs.

\section{Other Methods}

In addition to the mentioned-above synthesis methods, an increasing number of high-efficiency ways have been explored to prepare BMSs with different structures. For instance, sponge-like composite of $\left(\mathrm{ZnxCo}_{1-\mathrm{x}} \mathrm{S} \mathrm{QD} @ \mathrm{HCP}\right) @ \mathrm{rGO}$ were reported by Sun's group through a simultaneous thermal-induced sulfidation, carbonization, and reduction. The as-obtained $\mathrm{ZnxCo}_{1-\mathrm{x}} \mathrm{S}$ quantum dots (QD) were uniformly distributed on mesoporous hollow carbon polyhedral (HCP) matrix and rGO coating with large specific surface, denoted as $\left[\mathrm{ZnxCo}_{1-\mathrm{x}} \mathrm{S}\right.$ QD@HCP]@rGO (Figures 3A,B) (Chen Z. et al., 2017; Hwang et al., 2017). By using the solid state reaction method, Krengel synthesized $\mathrm{CuV}_{2} \mathrm{~S}_{4}$ particles with a broad size distribution between 5 and $50 \mu \mathrm{m}$ (Figure 3C). The obtained products delivered an excellent cycling stability of $580 \mathrm{mAh} \mathrm{g}^{-1}$ was retained after 500 cycles at $0.7 \mathrm{~A} \mathrm{~g}^{-1}$ and relatively high ICE of 72.5\% (Qin et al., 2016a; Xu et al., 2016; Zhou J. et al., 2016; Krengel et al., 2017).

With the novel methods developing to synthesize nanomaterials with unique structures, a plenty of BMSs with high-efficiency nanostructure have been applied in EES. A comparison of the structural properties, synthesis methods, and $S$ resource of BMSs is summarized in Table 2.

As mentioned, the nanomaterials obtained by a solvothermal method are characterized by good crystal morphology, controllable nanometer size, and high purity. However, it may be difficult to scale up the production. The spry pyrolysis results in the powder materials with the merits of small nanometer size and uniform dispersion, but this promising method needs some special equipment with complex operation. Despite some advantages of easy operation, low-cost and shorter reaction time, co-precipitation method still cause some challenges to solve, for example, the reaction rate is not controllable, with the server agglomeration of nanomaterials. Therefore, the desired and materials may be considered through choosing suitable synthesis strategies for BMSs (Lai et al., 2012; Palomares et al., 2012).

\section{APPLICATIONS IN SIBS}

\section{Transition BMSs}

Considering the specific reaction mechanism, abundant active sites and short diffusion path-ways, transition BMSs
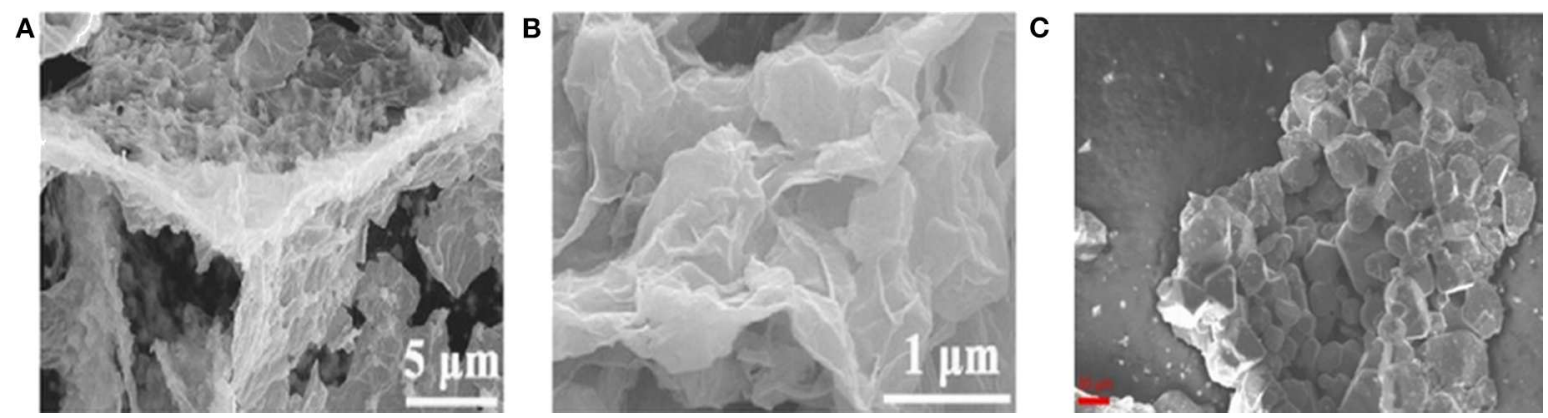

FIGURE 3 | (A,B) SEM images of [Zn $\mathrm{CO}_{1-x}$ S QD@HCP]@rGO composites. Reproduced with permission from Chen Z. et al. (2017) Copyright 2017. Wiley-VCH. (C) SEM image of $\mathrm{CuV}_{2} \mathrm{~S}_{4}$. Reproduced with permission from Krengel et al. (2017) Copyright 2017. American Chemical Society. 
TABLE 2 | Comparison between the structural properties, synthesis methods, and $\mathrm{S}$ resource of BMSs.

\begin{tabular}{|c|c|c|c|}
\hline Materials & $\begin{array}{l}\text { Morphology } \\
\text { \& Size (nm) }\end{array}$ & $\begin{array}{l}\text { Synthetic } \\
\text { method }\end{array}$ & S resource \\
\hline $\mathrm{NiCO}_{2} \mathrm{~S}_{4} @ \mathrm{NC}$ & $\begin{array}{l}\text { Nanoparticles } \\
9\end{array}$ & Hydrothermal & TAA \\
\hline $\mathrm{Ni}_{3} \mathrm{Co}_{6} \mathrm{~S}_{8}-\mathrm{rGO}$ & $\begin{array}{l}\text { Plate-shape } \\
\text { nanocrystals } \\
\text { - }\end{array}$ & $\begin{array}{l}\text { Ultrasonic } \\
\text { spray pyrolysis }\end{array}$ & Thiourea \\
\hline $\mathrm{NiCO}_{2} \mathrm{~S}_{4}-\mathrm{rGO}$ & $\begin{array}{l}\text { Hollow prism } \\
500-600\end{array}$ & $\begin{array}{l}\text { Refluxing \& } \\
\text { solvothermal }\end{array}$ & TAA \\
\hline $\begin{array}{l}\mathrm{Co}_{1} \mathrm{Zn}_{1}-\mathrm{S} \\
(600)\end{array}$ & $\begin{array}{l}\text { Nanocrystals } \\
-\end{array}$ & $\begin{array}{l}\text { Oil-bath \& } \\
\text { thermally treated }\end{array}$ & TAA \\
\hline $\mathrm{Co}_{8} \mathrm{FeS}_{8}$ & $\begin{array}{l}\text { Nanocubes } \\
100\end{array}$ & Wet chemical bath & Thiourea \\
\hline $\mathrm{Co}_{0.5} \mathrm{Fe}_{0.5} \mathrm{~S}_{2}$ & $\begin{array}{l}\text { Nanosphere } \\
\sim 100\end{array}$ & Solvothermal & Sublimed S \\
\hline $\begin{array}{l}\left(\mathrm{Zn}_{\mathrm{x}} \mathrm{Co}_{1-\mathrm{x}} \mathrm{S}\right. \\
\mathrm{QD} @ \mathrm{HCP}) @ \mathrm{rGO}\end{array}$ & $\begin{array}{l}\text { sponge-like } \\
\text { - }\end{array}$ & $\begin{array}{l}\text { Thermal-induced } \\
\text { sulfidation, } \\
\text { carbonization, and } \\
\text { reduction reaction }\end{array}$ & Sublimed S \\
\hline$(\mathrm{SnCo}) \mathrm{S}_{2} / \mathrm{SG}$ & $\begin{array}{l}\text { Nanocubes } \\
300-400\end{array}$ & annealing & Sublimed S \\
\hline $\begin{array}{l}\left(\mathrm{Ni}_{0.3} \mathrm{Co}_{0.7}\right)_{9} \mathrm{~S}_{8} / \mathrm{N}- \\
\mathrm{CNTS} / \mathrm{rGO}\end{array}$ & $\begin{array}{l}\text { Nanoparticles } \\
-\end{array}$ & $\begin{array}{l}\text { Coprecipitation/ } \\
\text { Hydrothermal }\end{array}$ & TAA \\
\hline $\mathrm{CuCO}_{2} \mathrm{~S}_{4} / \mathrm{rGO}$ & $\begin{array}{l}\text { Nanoparticles } \\
10-50\end{array}$ & Solvothermal & Thiourea \\
\hline $\begin{array}{l}\mathrm{Ti}_{0.25} \mathrm{Sn}_{0.75} \mathrm{~S}_{2} \\
@ \mathrm{MWCNTS}\end{array}$ & $\begin{array}{l}\text { Lantern-like } \\
750-850\end{array}$ & Hydrothermal & TAA \\
\hline $\mathrm{CoSnS}_{\mathrm{x}} @ \mathrm{NC}$ & $\begin{array}{l}\text { Nanoboxes } \\
\sim 150\end{array}$ & Solvothermal & TAA \\
\hline $\begin{array}{l}\text { N/S-rGO } \\
@ Z n \mathrm{ZnS}_{3}\end{array}$ & $\begin{array}{l}\text { Hollow } \\
\text { Nano-microcubes } \\
\sim 2,000\end{array}$ & $\begin{array}{l}\text { Coprecipitation/ } \\
\text { Hydrothermal }\end{array}$ & $\mathrm{Na}_{2} \mathrm{~S} /$ Thiourea \\
\hline Materials & $\begin{array}{l}\text { Morphology \& Size } \\
(\mathrm{nm})\end{array}$ & Synthetic method & S resource \\
\hline $\mathrm{VMo}_{2} \mathrm{~S}_{4}-\mathrm{rGO}$ & $\begin{array}{l}\text { Nanosheet } \\
-\end{array}$ & Solvothermal & TAA \\
\hline ZnSnS ${ }_{3} @$ rGO & $\begin{array}{l}\text { Nanoparticles } \\
-\end{array}$ & $\begin{array}{l}\text { Solvothermal \& } \\
\text { Annealing }\end{array}$ & Thiourea \\
\hline$\left(\mathrm{Co}_{0.5} \mathrm{Ni}_{0.5}\right)_{9} \mathrm{~S}_{8} / \mathrm{NC}$ & $\begin{array}{l}\text { Nanoparticles } \\
\text { \& Nanorods - }\end{array}$ & Solvothermal & Sulfur powder \\
\hline $\mathrm{Cu}_{2} \mathrm{MoS}_{4}$ & $\begin{array}{l}\text { Nanoparticles } \\
100\end{array}$ & Solvothermal & TAA \\
\hline $\mathrm{SnS}_{2} / \mathrm{Mn}_{2} \mathrm{SnS}_{4} / \mathrm{C}$ & $\begin{array}{l}\text { Nanoboxes } \\
100\end{array}$ & Coprecipitation & Sulfur powder \\
\hline $\mathrm{CuCO}_{2} \mathrm{~S}_{4}$ & $\begin{array}{l}\text { Sub-microspheres } \\
300-500\end{array}$ & Solvothermal & Thiourea \\
\hline $\mathrm{NiMo}_{3} \mathrm{~S}_{4} / \mathrm{CT}$ & $\begin{array}{l}\text { Nanosheets arrays } \\
3,000\end{array}$ & Hydrothermal & Thiourea \\
\hline$\left(\mathrm{Fe}_{0.5} \mathrm{Ni}_{0.5}\right)_{9} \mathrm{~S}_{8}$ & $\begin{array}{l}\text { Yolk-shell } \\
-\end{array}$ & Spray pyrolysis & Thiourea \\
\hline $\mathrm{Bi}_{0.94} \mathrm{Sb}_{1.06} \mathrm{~S}_{3}$ & Nanorod cluster & Hydrothermal & TAA \\
\hline $\mathrm{CuV}_{2} \mathrm{~S}_{4}$ & Nano-polyhedron & $\begin{array}{l}\text { Solid state } \\
\text { reaction }\end{array}$ & Sulfur powder \\
\hline
\end{tabular}

nanomaterials have many advantages as promising anode materials for SIBs. A large amount of work has been devoted to the development of transition BMSs anodes in SIBs. In this section, transition BMSs as high-performance SIB anode materials are discussed and reviewed.

In some case, a yolk-shell-structured $\mathrm{Fe}-\mathrm{Ni}-\mathrm{O}$ was designed via one-pot spray pyrolysis as shown in Figure 4A. When employed as an anode in SIBs, $\left(\mathrm{Fe}_{0.5} \mathrm{Ni}_{0.5}\right)_{9} \mathrm{~S}_{8}$ exhibited a capacity of $527 \mathrm{mAh} \mathrm{g}^{-1}$ at $1 \mathrm{~A} \mathrm{~g}^{-1}$ after 100 cycles. An outstanding rate performance was also obtained with a reversible discharge capacity of $465 \mathrm{mAh} \mathrm{g}^{-1}$ at $5.0 \mathrm{~A} \mathrm{~g}^{-1}$ (Kim and Kang, 2017). Kang et al. investigated cobalt doped $\mathrm{FeS}_{2}$ through changing the content of Co by a simple solvothermal method. When employed as an anode material in SIBs for the first time, the Co doped $\mathrm{FeS}_{2}$ showed a good cycling and rate performance in a voltage range of $0.8-2.9 \mathrm{~V}$ owing to the high rate capability of $\mathrm{FeS}_{2}$ and high capacity of $\mathrm{CoS}_{2}$. All samples displayed spherical particle shapes with average diameters of about $100 \mathrm{~nm}$ (Figures 4B,C). When Co contents increased to $0.5, \mathrm{Co}_{0.5} \mathrm{Fe}_{0.5} \mathrm{~S}_{2}$ showed the best electrochemical performances. As shown in Figures 4D,E, a stable specific capacity of $220 \mathrm{mAh} \mathrm{g}^{-1}$ was achieved after 5,000 cycles at $2 \mathrm{~A} \mathrm{~g}^{-1}$ (Zhang et al., 2016; Ge et al., 2017). Feng et al. used a simple solvothermal method to synthesize $\mathrm{CuCo}_{2} \mathrm{~S}_{4}$ sub-microspheres with the sizes ranged from 300 to $500 \mathrm{~nm}$ (Figure 4F). The unique structure and dual metal synergistic effects of $\mathrm{CuCo}_{2} \mathrm{~S}_{4}$ can effectively improve the stability of electrode materials by avoiding aggregation of nanomaterials and shortening the ion/electron diffusion pathways. The obtained $\mathrm{CuCo}_{2} \mathrm{~S}_{4}$ composite displayed an excellent cycling stability and high coulombic efficiency as anode for SIBs Figure 4G ( $\mathrm{Li}$ Q. et al., 2019). As depicted in the inset of Figure $\mathbf{4 H}$, an irregular micro-polyhedron $\mathrm{CuV}_{2} \mathrm{~S}_{4}$ was synthesized via a solid state reaction method. The cycling capability of the $\mathrm{CuV}_{2} \mathrm{~S}_{4}$ as shown in Figure $4 \mathbf{H}$, which displays a capacity of $490 \mathrm{mAh} \mathrm{g}^{-1}$ at $0.15 \mathrm{~A}$ $\mathrm{g}^{-1}$ and $410 \mathrm{mAh}^{-1}$ at $0.7 \mathrm{~A} \mathrm{~g}^{-1}$. The intermediate product $\mathrm{Na}_{2} \mathrm{~S}$ matrix starts to participate in the redox process causing a stable capacity increase up to $580 \mathrm{mAh} \mathrm{g}^{-1}$ during the first 250 cycles at $0.7 \mathrm{~A} \mathrm{~g}^{-1}$ and maintaining it at this level during the next 50 cycles (Krengel et al., 2017).

In conclusion, the abundance of transition metals with different valence states makes them exhibit a high theoretical specific capacity during the electrochemical reactions.

Despite the many advantages of BMSs, the challenges still remain in terms of sluggish reaction kinetics, bad electrochemical properties due to the large radius of $\mathrm{Na}^{+}$ and considerable volume-change during the cycling process. To overcome the pitfalls mentioned above, carbon-based materials were introduced because of their cycling stability, wide-abundant resources, and low sodium embedded platform. Indeed, coating and doping BMSs with carbon materials have been employed as promising methods for enhancing the sodium ions storage performance in SIBs because they can improve the electroconductivity and maintain the structural stability of BMSs (Chen S. et al., 2017; Lin et al., 2018; Lv et al., 2018; Zhang et al., 2018).

As a typical $\mathrm{BMS}, \mathrm{NiCo}_{2} \mathrm{~S}_{4}$ has drawn much attention due to its excellent electroconductivity, extremely stable electrochemical cycling performance and outstanding rate capability. Nonetheless, its sluggish $\mathrm{Na}^{+}$kinetics has limited the advancement of this anode material. To overcome this issue, 
A

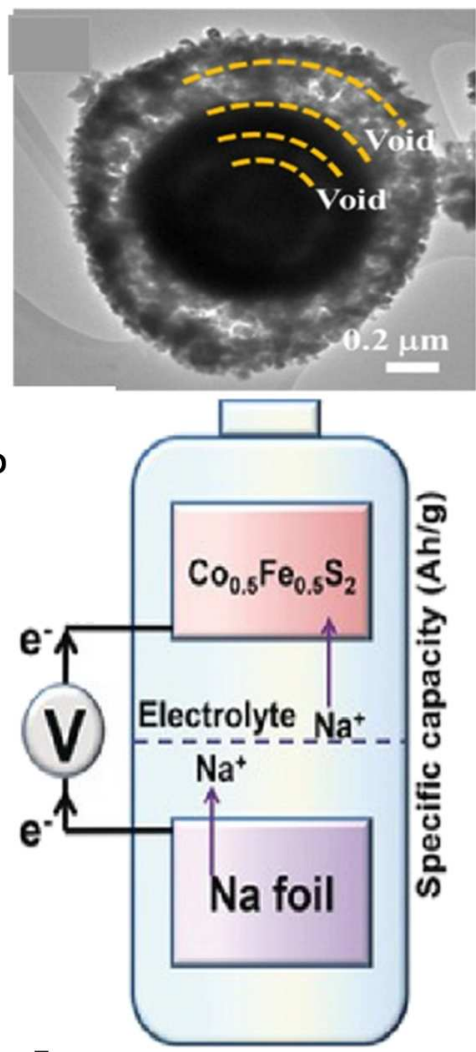

$\mathbf{F}$

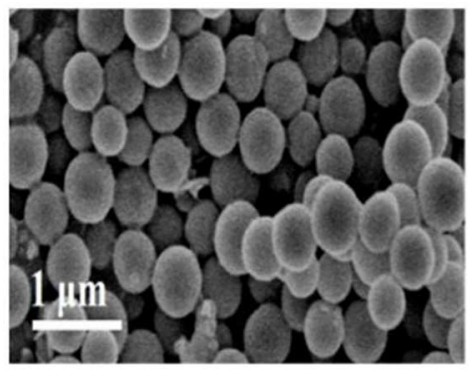

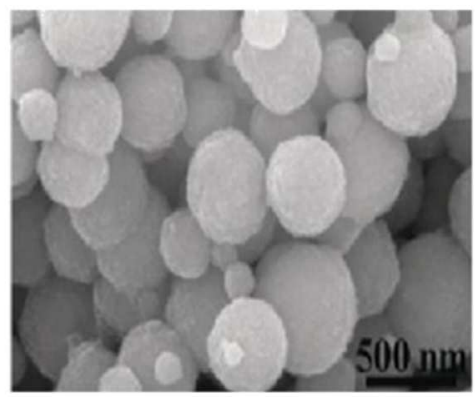

C

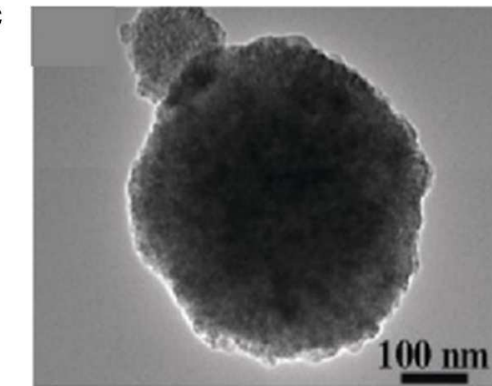

E

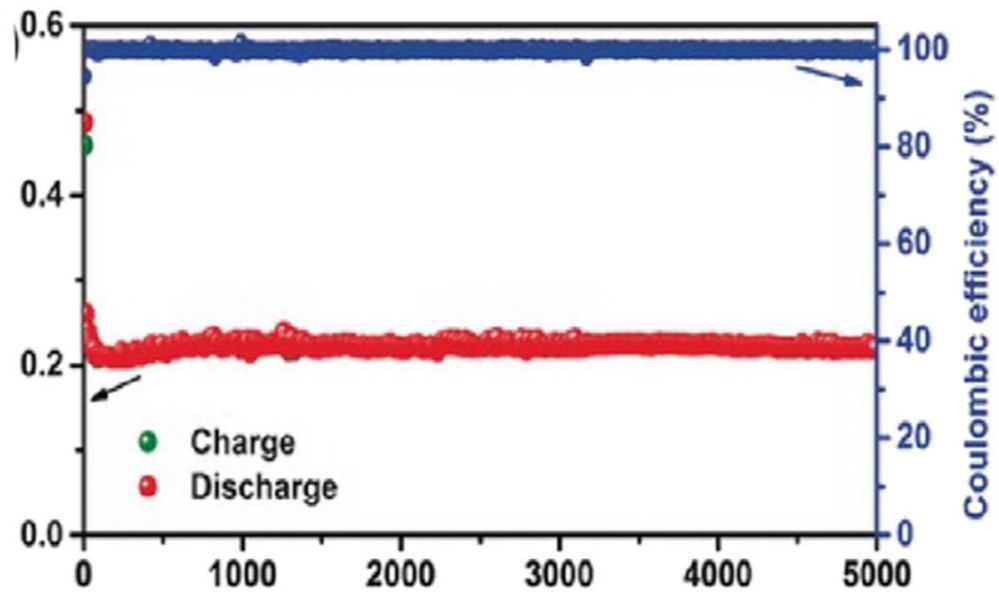

Cycle number (n)
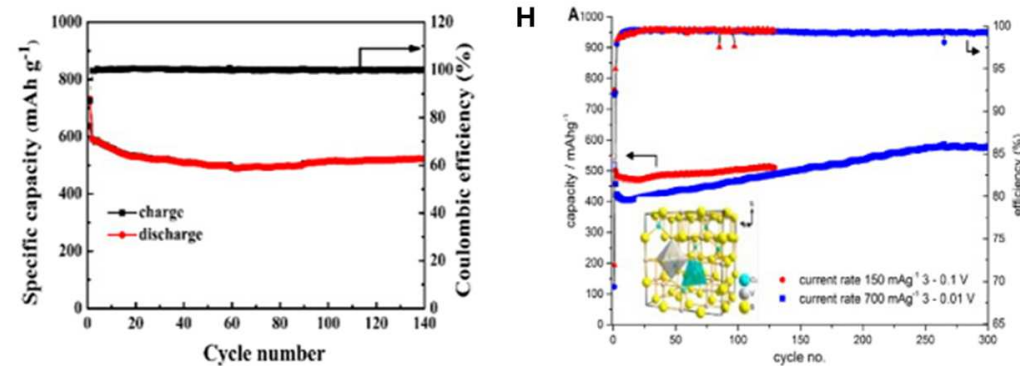

FIGURE 4 | (A) TEM images of the ( $\left.\mathrm{Fe}_{0.5} \mathrm{Ni}_{0.5}\right)_{9} \mathrm{~S}_{8}$ yolk-shell powder. Reproduced with permission from Kim and Kang (2017) Copyright 2017, Tsinghua University Press. (B,C) SEM and TEM images of the $\mathrm{CO}_{0.5} \mathrm{Fe}_{0.5} \mathrm{~S}_{2}$ sample. (D,E) lllustration of the composition and cycling performance of $\mathrm{Na} / \mathrm{Co}_{0.5} \mathrm{Fe}_{0.5} \mathrm{~S}_{2}$ half-cell. Reproduced with permission from Zhang et al. (2016) Copyright 2016, Wiley-VCH. (F) SEM image of the $\mathrm{CuCO}_{2} \mathrm{~S}_{4}$ sub-microspheres; (G) Cycling performance of $\mathrm{CuCO}_{2} \mathrm{~S}_{4}$. Reproduced with permission from Li Q. et al. (2019) Copyright 2019, Wiley-VCH. (H) Cycling performance and coulombic efficiency of CuV $\mathrm{S}_{4}$ cells, using galvanostatic cycling at $0.15 \mathrm{~A} \mathrm{~g}^{-1}$ between 3 and $0.1 \mathrm{~V}$ and 3 and $0.01 \mathrm{~V}$ at $0.7 \mathrm{~A} \mathrm{~g}^{-1}$. The inset in $\mathbf{( H )}$ shows the spinel type unit cell. Reproduced with permission from Krengel et al. (2017) Copyright 2017, American Chemical Society.

the composites of $\mathrm{NiCo}_{2} \mathrm{~S}_{4}$ with $\mathrm{C}$-based materials, such as $\mathrm{N}$-doped carbon (NC), rGO and carbon nanotubes (CNTs) have been investigated. The carbon-based materials can not only improve the electroconductivity, but also provide more active sites for fast $\mathrm{Na}^{+}$storage and alleviate the volume expansion during the charge-discharge process (Xiao et al., 2017). For instance, Yin et al. reported the effectiveness of rGO matrix in enhancing electrochemical properties of $\mathrm{NiCo}_{2} \mathrm{~S}_{4}$ hollow prism confirmed by its cycling performance (Figure 5A). During the discharge process, the hollow $\mathrm{NiCo}_{2} \mathrm{~S}_{4}$ shell nanoparticles will be collapsed when $\mathrm{Na}^{+}$inserts into the anode, while the $\mathrm{NiCo}_{2} \mathrm{~S}_{4}$ nanomaterial wrapped in rGO can be well-preserved (Figure 5B) (Zhang et al., 2018). Therefore, ultrathin rGO nanosheets with large specific surface area, active site and porous channels lead to an outstanding electrochemical performance with a well Na-storage. Figure 5C illustrates the cycling performance of $\mathrm{Ni}_{3} \mathrm{Co}_{6} \mathrm{~S}_{8} @ \mathrm{rGO}$ electrode at $0.5 \mathrm{~A} \mathrm{~g}^{-1}$ prepared by Kang et al. with distributing the plate-shape nanocrystals of $\mathrm{Ni}_{3} \mathrm{Co}_{6} \mathrm{~S}_{8}$ over the crumpled rGO structure. These nanocrystals delivered a capacity of $298.1 \mathrm{mAh} \mathrm{g}^{-1}$ after 300 cycles at $25 \mathrm{mAh} \mathrm{g}^{-1}$ as anode material in SIBs (Choi and Kang, 2015b). $\mathrm{CuCo}_{2} \mathrm{~S}_{4} / \mathrm{rGO}$ nanocomposites were synthesized, which displayed a capacity 


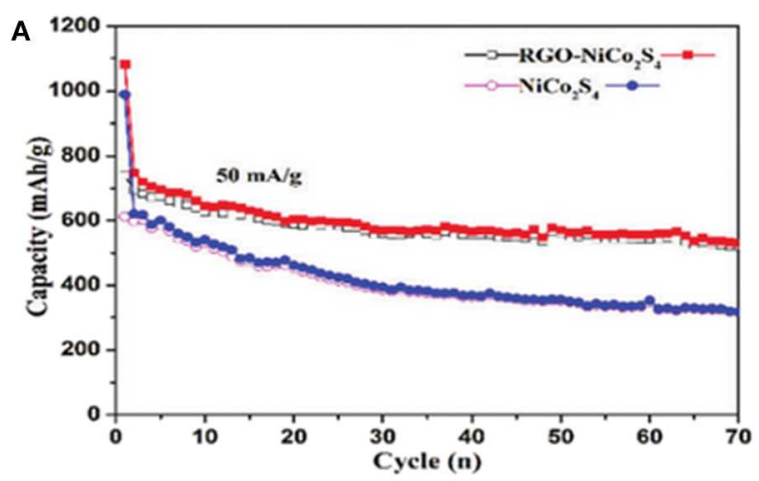

B

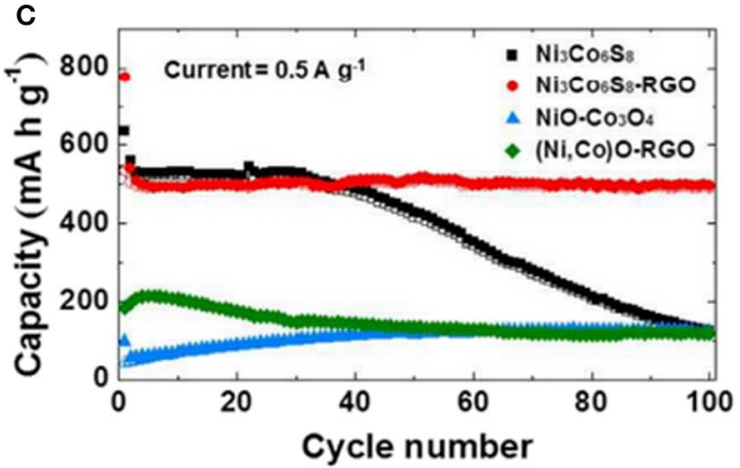

D
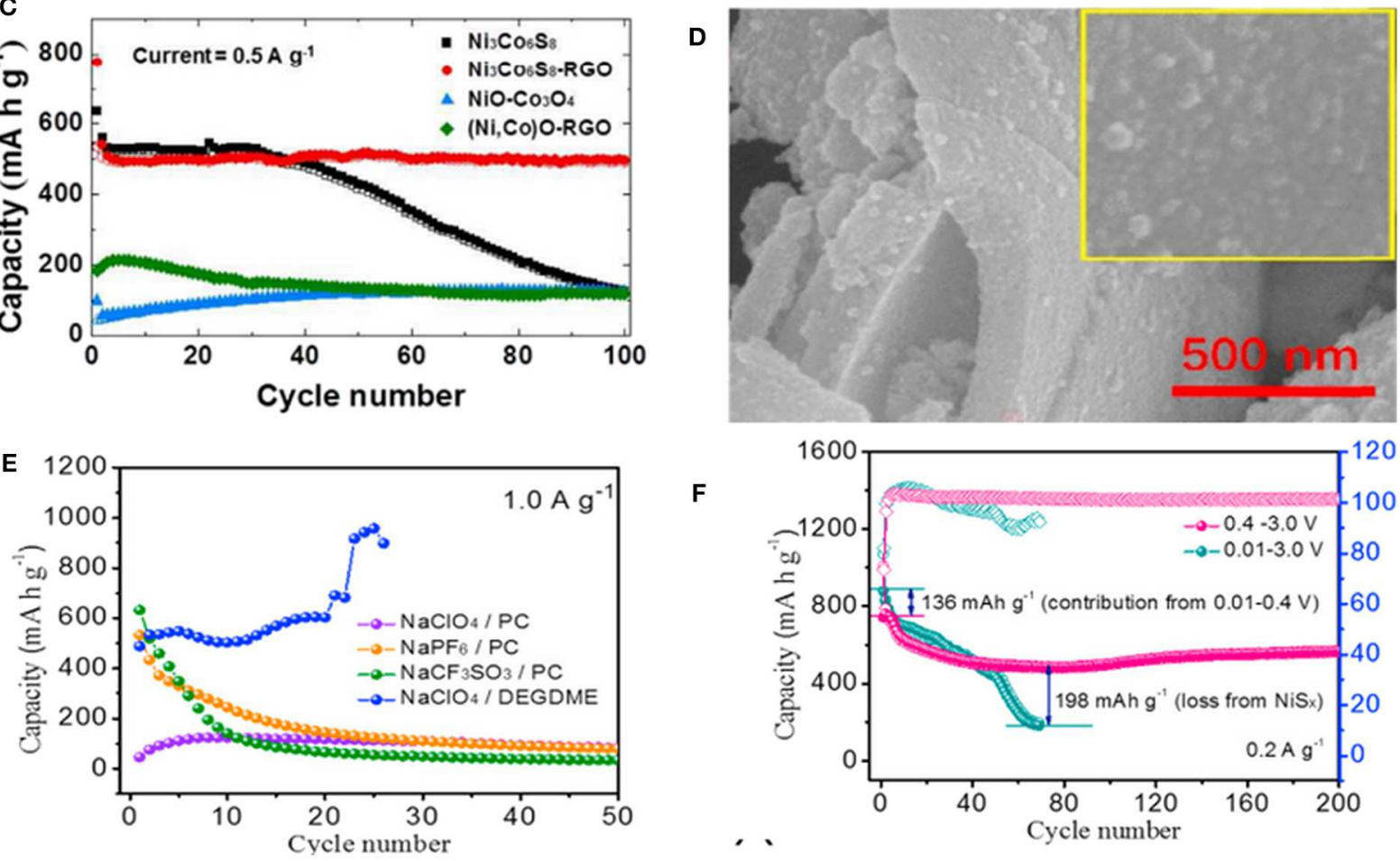

FIGURE 5 | (A) The cycling performance of $\mathrm{NiCO}_{2} \mathrm{~S}_{4}$ and $\mathrm{rGO}-\mathrm{NiCO}_{2} \mathrm{~S}_{4}$ at $50 \mathrm{~mA} \mathrm{~g}^{-1}$. (B) Schema of Na-ion insertion process in $\mathrm{NiCO}_{2} \mathrm{~S}_{4}$ and rGO-NiCo $\mathrm{S}_{4}$. Reproduced with permission from Zhang et al. (2018) Copyright 2018. Royal Society of Chemistry. (C) Cycling performances of $\left(\mathrm{Ni}_{1}, \mathrm{Co}\right) \mathrm{O}-\mathrm{rGO}$ and $\mathrm{Ni}_{3} \mathrm{Co}_{6} \mathrm{~S}_{8}-\mathrm{rGO}$ at $0.5 \mathrm{~A} \mathrm{~g}^{-1}$. Reproduced with permission from Choi and Kang (2015a) Copyright 2015. Royal Society of Chemistry. (D) SEM images of $\mathrm{NiCO}_{2} \mathrm{~S}_{4}-\mathrm{NC}$, (E) Cycling performances of $\mathrm{NiCO}_{2} \mathrm{~S}_{4}-\mathrm{NC}$ in different electrolytes at $1.0 \mathrm{~A} \mathrm{~g}^{-1}$, (F) Cycling performance and coulombic efficiency of $\mathrm{NiCO}_{2} \mathrm{~S}_{4}-\mathrm{NC}$ in different cut-off voltage windows at $0.2 \mathrm{~A} \mathrm{~g}^{-1}$. Reproduced with permission from Li S. et al. (2019) Copyright 2019. Elsevier.

of $433 \mathrm{mAh} \mathrm{g}^{-1}$ after 50 cycles at $0.1 \mathrm{~A} \mathrm{~g}^{-1}$ and delivered an excellent rate performance with $336 \mathrm{mAh} \mathrm{g}^{-1}$ at $1 \mathrm{~A} \mathrm{~g}^{-1}$ (Gong et al., 2018).

Moreover, combining with graphene, Ji et al. utilized a bottom-up strategy for preparing $\mathrm{NiCo}_{2} \mathrm{~S}_{4}$ nanodots uniformly incorporated with $\mathrm{N}$-doped carbon (denoted as $\mathrm{NiCo}_{2} \mathrm{~S}_{4}$ NC) (Figure 5D). Then, the influence of different electrolytes and voltage windows on its electrochemical performance was investigated. As shown in Figure 5E, due to the flexible onedimensional chain structure of DEGDME, the cell with the ether-based $\mathrm{NaClO}_{4} / \mathrm{DEGDME}$ electrolyte delivered the highest capacity of $530 \mathrm{mAh} \mathrm{g}^{-1}$ at $1.0 \mathrm{~A} \mathrm{~g}^{-1}$. Indeed, the best voltage range was realized to be $0.4-3.0 \mathrm{~V}$, in which the cell can effectively maintain a reversible phase transformation and avoid the side reaction (Figure 5F) (Li S. et al., 2019). Chen et al. also synthesized $\mathrm{N}$-doped carbon coated $\mathrm{Co}_{8} \mathrm{FeS}_{8}$ hollow nanocubes with large surface area, small charge transfer resistance, and fast $\mathrm{Na}^{+}$diffusion coefficient. Moreover, a layered $\mathrm{Cu}_{2} \mathrm{MoS}_{4}$-rGO with crystal structure was prepared by this group (Chen et al., 2019).

$\mathrm{Co}_{1} \mathrm{Zn}_{1}-\mathrm{xS}(600)$ is another unique composite structure prepared through a simple sulfidation and calcination. This special structure can retard the volume-change during the electrochemical process, expediate the $\mathrm{Na}^{+}$diffusion kinetics and enhance the electroconductivity, leading to a relatively low irreversible capacity, and superior cycling and rate performance 
(Figure 6A). When used in SIBs, an excellent capacity of 542 $\mathrm{mAh} \mathrm{g}^{-1}$ can be achieved after 100 cycles at $0.1 \mathrm{~A} \mathrm{~g}^{-1}$, with an impressive rate property of $219.3 \mathrm{mAh} \mathrm{g}^{-1}$ at $10 \mathrm{~A} \mathrm{~g}^{-1}$ (Choi et al., 2015; Qin et al., 2016b; Fang G. et al., 2018; Wang et al., 2018). In another study, a sponge-like $\left(\mathrm{Zn}_{\mathrm{x}} \mathrm{Co}_{1-\mathrm{x}} \mathrm{S}\right.$ QD@HCP)@rGO composite combined with mesoporous hollow carbon polyhedral (HCP) matrix and rGO wrapped sheets was prepared. Due to the merits of this structure, $\left(\mathrm{Zn}_{\mathrm{x}} \mathrm{Co}_{1-\mathrm{x}} \mathrm{S}\right.$ QD@HCP)@rGO as a binder-free anode in SIBs showed a good reversible capacity and cycling performance (i.e., $638 \mathrm{mAh} \mathrm{g}^{-1}$ at $0.3 \mathrm{~A} \mathrm{~g}^{-1}$ after 500 cycles), which was better than that of the monometallic sulfide under the same conditions (Figure 6B) (Chen Z. et al., 2017). In order to solve the problems of low energy density and poor cycle life when used as an anode in SIBs, MOF precursors were utilized to fabricate in-situ NC embellished with BMS hollow spheres nanomaterials. They prepared $\left(\mathrm{Co}_{0.5} \mathrm{Ni}_{0.5}\right)_{9} \mathrm{~S}_{8}$ solid-solution combined with in-situ $\mathrm{NC}$ [donated as $\left(\mathrm{Co}_{0.5} \mathrm{Ni}_{0.5}\right){ }_{9} \mathrm{~S}_{8} / \mathrm{NC}$ ], which exhibited a superior $\mathrm{Na}$-storage properties. Indeed, a good specific capacity of 723.7 $\mathrm{mAh} \mathrm{g}^{-1}$ was maintained after 100 cycles at $1 \mathrm{~A} \mathrm{~g}^{-1}$, with $83 \%$ coulombic efficiency compared to the second cycle. The impressive rate capability of $596.1 \mathrm{mAh} \mathrm{g}^{-1}$ was achieved at $10 \mathrm{~A} \mathrm{~g}^{-1}$ with a high capacity retention of $60.2 \%$ at $0.1 \mathrm{~A} \mathrm{~g}^{-1}$, demonstrating an excellent rate performance. As a result of carbon modification and the hierarchical sphere structures, high electrical conductivity, and mechanical stability were achieved during the cycling process (Cao et al., 2019).

Because of the inherent disadvantages of BMSs, the electrode materials are highly susceptible to expansion and then easily detached from the current collector during the cycling. The related results demonstrated that carbon modification and optimization of the nanostructure are good choices to obtain high performance sodium ions storage system. In addition, Yang et al. designed a bind-free electrode material as SIBs anode, which has a $\mathrm{NiMo}_{3} \mathrm{~S}_{4} / \mathrm{CTs}$ nanosheet arrays with hierarchical hybrid nanostructure (Kong et al., 2018). Consequently, it delivered a high sodium storage capacity and an excellent cycling performance.

In the past decade, a large amount of studies has been done to explore excellent electrode materials for $\mathrm{Na}$-storage. Hence, a detailed comparison of the electrochemical performance of BMS anodes in SIBs are presented in Table 3.

\section{Mixed BMSs}

Tin-based BMSs $\left(\mathrm{ZnSnS}_{3}, \mathrm{CoSnS}_{\mathrm{x}}\right)$ have shown high capacity as SIB anodes, and attracted extensive attention due to the large interlayer spacing originated from their CdI2-type layered structure, and high theoretical capacity owing to the combination of conversion and alloying types electrochemical reaction mechanism (Qu et al., 2014; Choi et al., 2015; Cho et al., 2016; Lu et al., 2016). However, it is essential to resolve the problems rooted in large volume expansion and their low conductivity. Therefore, structure engineering and introduction of carbon materials have been sought to change the electrochemical properties of BMSs.

Zinc tin sulfide@rGO $\left(\mathrm{ZnSnS}_{3} @ \mathrm{rGO}\right)$ nanoparticles were prepared by Zhang et al. via combining solvothermal reaction with the annealing process. When used in SIBs, superior Nastorage performance with large specific capacity $(472.2 \mathrm{mAh}$ $\mathrm{g}^{-1}$ at $\left.0.1 \mathrm{~A} \mathrm{~g}^{-1}\right)$, high rate capability $\left(165.8 \mathrm{mAh}^{-1}\right.$ at $2 \mathrm{~A}$

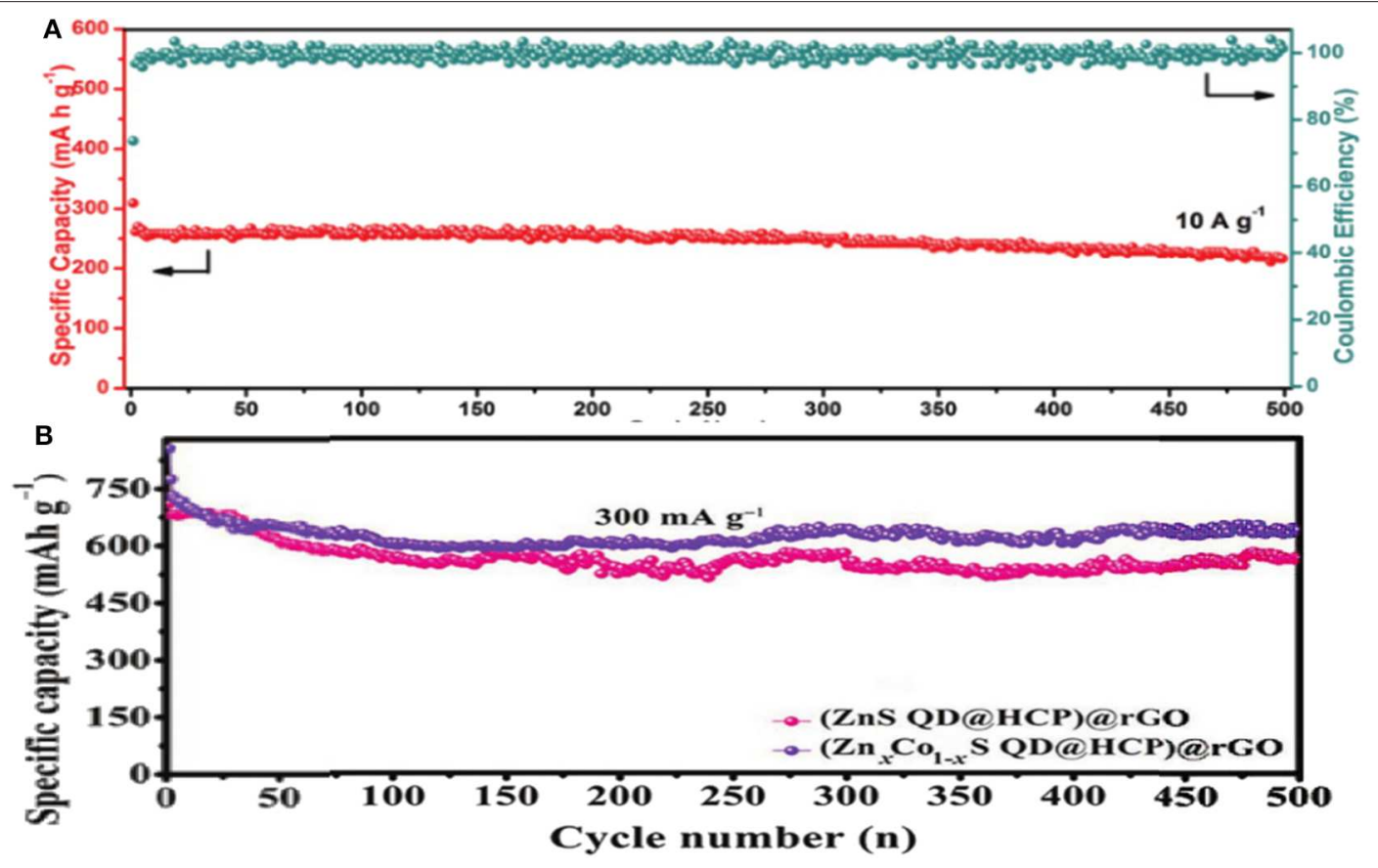

FIGURE 6 | (A) Cycling performance of $\mathrm{Co}_{1} \mathrm{Zn}_{1}-\mathrm{xS}$. Reproduced with permission from Fang G. et al. (2018) Copyright 2018. Wiley-VCH. (B) Cycling performance of (ZnS QD@HCP)@rGO and ( $\mathrm{Zn}_{x} \mathrm{CO}_{1-x} \mathrm{~S}$ QD@HCP)@rGO composites at $3 \mathrm{~A} \mathrm{~g}^{-1}$. Reproduced with permission from Chen Z. et al. (2017) Copyright 2017. Wiley-VCH. 
TABLE 3 | Comparison between the electrochemical performance of BMS anodes in SIBs.

\begin{tabular}{|c|c|c|c|c|}
\hline Materials & $\begin{array}{l}\text { Current density } \\
\qquad\left[\mathrm{mA} \mathrm{g}^{-1}\right]\end{array}$ & $\begin{array}{l}\text { Cycle } \\
\text { number }\end{array}$ & $\begin{array}{c}\text { Cut-off } \\
\text { voltage } \\
\text { [V] }\end{array}$ & $\begin{array}{c}\text { Specific } \\
\text { capacity } \\
{\left[\mathrm{mA} \mathrm{h} \mathrm{g} \mathbf{~}^{-1}\right]}\end{array}$ \\
\hline \multirow[t]{3}{*}{$\mathrm{NiCO}_{2} \mathrm{~S}_{4} @ \mathrm{NC}$} & $\begin{array}{c}100 \\
6,000\end{array}$ & $\begin{array}{c}200 \\
5,000\end{array}$ & $0.4-3$ & $\begin{array}{l}570.1 \\
395.6\end{array}$ \\
\hline & 100 & 1 & $\begin{array}{l}0.4-3 \\
0.01-3\end{array}$ & $\begin{array}{l}742.2 \\
878.2\end{array}$ \\
\hline & & 70 & $\begin{array}{l}0.4-3 \\
0.01-3\end{array}$ & $\begin{array}{l}570.1 \\
181.3\end{array}$ \\
\hline $\mathrm{Ni}_{3} \mathrm{Co}_{6} \mathrm{~S}_{8}-\mathrm{RGO}$ & 500 & $\begin{array}{c}2 \\
100\end{array}$ & $0.001-3$ & $\begin{array}{l}504 \\
498\end{array}$ \\
\hline $\mathrm{Ni}_{3} \mathrm{Co}_{6} \mathrm{~S}_{8}$ & & $\begin{array}{c}2 \\
100\end{array}$ & & $\begin{array}{l}522 \\
125\end{array}$ \\
\hline $\mathrm{NiCO}_{2} \mathrm{~S}_{4} @ \mathrm{RGO}$ & 50 & $\begin{array}{l}20 \\
70\end{array}$ & $0.01-3$ & $\begin{array}{l}603.5 \\
530.2\end{array}$ \\
\hline $\mathrm{NiCO}_{2} \mathrm{~S}_{4}$ & & $\begin{array}{l}20 \\
70\end{array}$ & & $\begin{array}{c}462.1 \\
317\end{array}$ \\
\hline \multirow[t]{2}{*}{$\mathrm{Co}_{1} \mathrm{Zn}_{1}-\mathrm{S}(600)$} & 100 & $\begin{array}{c}1 \\
100\end{array}$ & $0.01-3$ & $\begin{array}{l}745 \\
542\end{array}$ \\
\hline & 10,000 & 5,000 & & 219.3 \\
\hline \multirow[t]{2}{*}{$\mathrm{Co}_{8} \mathrm{FeS}_{8}$} & 50 & 40 & $0.01-3$ & $\approx 500$ \\
\hline & 500 & 150 & & 87 \\
\hline \multirow[t]{2}{*}{$\mathrm{Co}_{0.5} \mathrm{Fe}_{0.5} \mathrm{~S}_{2}$} & 100 & 60 & $0.8-2.9$ & 328 \\
\hline & 2,000 & 5,000 & & 220 \\
\hline $\begin{array}{l}\left(\mathrm{Zn}_{\mathrm{x}} \mathrm{CO}_{1-\mathrm{x}} \mathrm{S}\right. \\
\mathrm{QD} @ \mathrm{HCP}) @ \mathrm{rGO}\end{array}$ & 300 & 500 & $0.01-2.9$ & 638 \\
\hline \multirow[t]{2}{*}{$(\mathrm{SnCo}) \mathrm{S}_{2} / \mathrm{SG}$} & 500 & 300 & $0.01-3$ & 593 \\
\hline & 5,000 & 5,000 & & 487 \\
\hline $\begin{array}{l}\left(\mathrm{Ni}_{0.3} \mathrm{Co}_{0.7}\right)_{9} \mathrm{~S}_{8} / \mathrm{N}- \\
\mathrm{CNTs} / \mathrm{rGO}\end{array}$ & 25 & 300 & $0.01-3$ & 298.1 \\
\hline $\mathrm{CuCO}_{2} \mathrm{~S}_{4} / \mathrm{rGO}$ & 100 & 50 & $0.01-2.5$ & 433 \\
\hline \multirow{2}{*}{$\begin{array}{l}\mathrm{Ti}_{0.25} \mathrm{Sn}_{0.75} \mathrm{~S}_{2} \\
@ \mathrm{MWCNTs}\end{array}$} & 200 & 50 & $0.01-2.5$ & 307 \\
\hline & 400 & 1,000 & & 388 \\
\hline \multirow[t]{2}{*}{$\mathrm{CoSnS}_{\mathrm{x}} @ \mathrm{NC}$} & 200 & 500 & $0.01-3$ & 300 \\
\hline & 1,000 & 4,000 & & 180 \\
\hline \multirow[t]{2}{*}{ N/S-rGO@ZnSnS 3} & 100 & 100 & $0.01-3$ & 501.7 \\
\hline & 1,000 & 500 & & 290.7 \\
\hline $\mathrm{VMo}_{2} \mathrm{~S}_{4}-\mathrm{rGO}$ & 1,000 & 200 & $0.01-3$ & 254 \\
\hline ZnSnS $3 @$ rGO & 100 & 200 & $0.01-2.5$ & 401.2 \\
\hline$\left(\mathrm{Co}_{0.5} \mathrm{Ni}_{0.5}\right)_{9} \mathrm{~S}_{8} / \mathrm{NC}$ & 50 & 100 & $0.01-3$ & 569.9 \\
\hline $\mathrm{Cu}_{2} \mathrm{MoS}_{4}$ & 500 & 2,000 & $0.5-3$ & 205.7 \\
\hline $\mathrm{SnS}_{2} / \mathrm{Mn}_{2} \mathrm{SnS}_{4} / \mathrm{C}$ & 5,000 & 500 & $0.1-3$ & 522.5 \\
\hline $\mathrm{CuCO}_{2} \mathrm{~S}_{4}$ & 200 & 140 & $0.01-3$ & 522.4 \\
\hline $\mathrm{NiMO}_{3} \mathrm{~S}_{4} / \mathrm{CT}$ & 480 & 1,000 & $0.01-3$ & 302 \\
\hline$\left(\mathrm{Fe}_{0.5} \mathrm{Ni}_{0.5}\right)_{9} \mathrm{~S}_{8}$ & 1,000 & 100 & $0.01-3$ & 527 \\
\hline $\mathrm{Bi}_{0.94} \mathrm{Sb}_{1.06} \mathrm{~S}_{3}$ & 1,000 & 100 & $0.01-2.8$ & 380 \\
\hline \multirow[t]{2}{*}{$\mathrm{CuV}_{2} \mathrm{~S}_{4}$} & 150 & 150 & $0.1-3$ & 500 \\
\hline & 700 & 300 & $0.01-3$ & 580 \\
\hline
\end{tabular}

$\left.\mathrm{g}^{-1}\right)$, and ultralong cycle life (401.2 $\mathrm{mAh}^{-1}$ at $0.1 \mathrm{~A} \mathrm{~g}^{-1}$ after 200 cycles) was achieved (Jia et al., 2018). Therefore, the introduced composite anode design provides new changes for development of highly stable anode materials which possess excellent conductivities and high adaptability for large volumechanges during the sodiation/desodiation process. Liu et al. designed $\mathrm{ZnSnS}_{3}$ nanostructure with hollow nano-microcubes through co-precipitation and hydrothermal methods. The process was followed by coating the N/S dual-doped rGO (N/SrGO@ $\mathrm{ZnSnS}_{3}$ ) (Figures 7A,B) to enhance the slow reaction kinetics, poor electrochemical properties of the BMS. As a result, the prepared N/S-rGO@ $\mathrm{ZnSnS}_{3}$ composite exhibited a high specific capacity of $501.7 \mathrm{mAh} \mathrm{g}^{-1}$ after 100 cycles at $0.1 \mathrm{~A} \mathrm{~g}^{-1}$ and an excellent long cycle life of $290.7 \mathrm{mAh} \mathrm{g}^{-1}$ after 500 cycles at $1 \mathrm{~A} \mathrm{~g}^{-1}$. Meanwhile, a high-rate capacity of $256.6 \mathrm{mAh} \mathrm{g}^{-1}$ at $2 \mathrm{~A} \mathrm{~g}^{-1}$ was maintained (Figures 7C,D). Such outstanding performances were primarily ascribed to the coating of dualdoped rGO which provides some synergetic merits for EES as follows: (1) due to the strong polarity of the doping area that restraining the aggregation of the prepared $\mathrm{rGO}$; (2) enhancing the electroconductivity by reducing the semiconducting gap; (3) because of the deficiencies possess high-electronegativity can easily attract the positive ions that leading to increase the number of alkali metal ions; (4) owing to the adsorption effect among anode and rGO that reinforcing the structural stability (Liu et al., 2019). In addition, Chen et al. introduced titanium into the crystal structure of $\mathrm{SnS}_{2}$ to partially replace tin, forming the lantern-like $\mathrm{Ti}_{0.25} \mathrm{Sn}_{0.75} \mathrm{~S}_{2}$ followed by coating one-dimensional multi-walled carbon nanotubes (MWCNTs) (denoted as $\mathrm{Ti}_{0.25} \mathrm{Sn}_{0.75} \mathrm{~S}_{2} @ M W C N T s$ ) to improve the defects of $\mathrm{SnS}_{2}$ volume expansion and low conductivity. Profiting from its lantern-like structure with a large specific surface area, the electrolyte could fully infiltrate into $\mathrm{Ti}_{0.25} \mathrm{Sn}_{0.75} \mathrm{~S}_{2} @ M W C N T s$, increasing the electron/ion transfer during cycling. A high specific capacity of $307 \mathrm{mAh} \mathrm{g}^{-1}$ was acquired after 1,000 cycles at $0.4 \mathrm{~A} \mathrm{~g}^{-1}$ during the electrochemical testing process (Huang et al., 2018). The single-crystal mesoporous $\mathrm{CoSn}(\mathrm{OH})_{6}$ nanoboxes were also synthesized through co-precipitation. TAA was employed as $S$ resource to reach $\mathrm{CoSnSx}$ via solvothermal method, followed by polymer nanoplating and carbonization with dopamine at higher temperature in $\mathrm{N}_{2}$ flow to obtain $\mathrm{CoSnS}_{\mathrm{x}} @ \mathrm{NC}$ electrode materials. Subsequently, the $\mathrm{Na}$-storage performance and influence of carbon content on the electrochemical properties of $\mathrm{CoSnS}_{\mathrm{x}} @ \mathrm{NC}$ nanoboxes were investigated. The results indicated that the best amount of carbon content is $36.8 \mathrm{wt} . \%$ to protect the nanoboxes from destruction during deep cycling. The electrode exhibited an excellent cycling performance and achieved a high capacity of $300 \mathrm{mAh} \mathrm{g}^{-1}$ with a high coulombic efficiency of nearly $100 \%$ after 500 cycles, as well as an outstanding long-life cycling of $180 \mathrm{mAh} \mathrm{g}^{-1}$ after 4,000 cycles at $1 \mathrm{~A} \mathrm{~g}^{-1}$ (Figure 7E) (Liu et al., 2017). Moreover, $\mathrm{Ou}$ et al. prepared heterostructured $\mathrm{SnS}_{2} / \mathrm{Mn}_{2} \mathrm{SnS}_{4} /$ carbon nanoboxes with about $100 \mathrm{~nm}$ in size through a facial coprecipitation method. When evaluated as an anode material in SIBs, the special structure between $\mathrm{SnS}_{2}$ and $\mathrm{Mn}_{2} \mathrm{SnS}_{4}$ can alleviate the volume change upon a mass of electrochemical process, prevent the cohesion of $\mathrm{Sn}$ nanoparticles, and boost the reversibility of conversion-alloying reaction. It also demonstrated a high ICE of $90.8 \%$, an outstanding long cycling stability of $522.5 \mathrm{mAh} \mathrm{g}^{-1}$ after 500 cycles at $5 \mathrm{~A} \mathrm{~g}^{-1}$, and a remarkable 
A

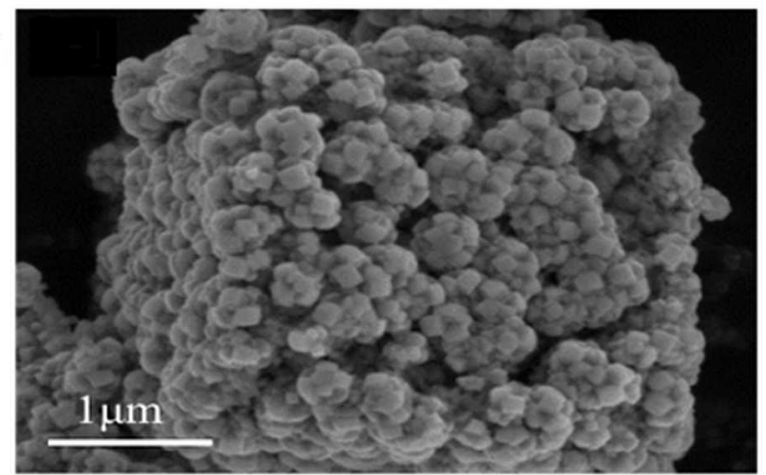

C

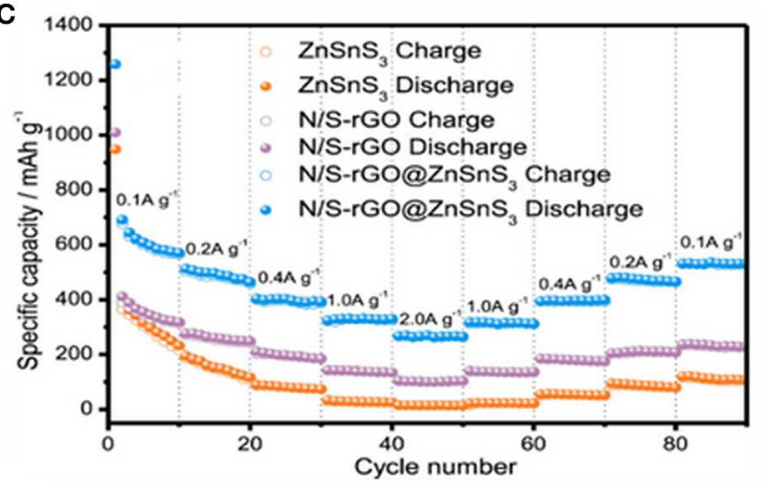

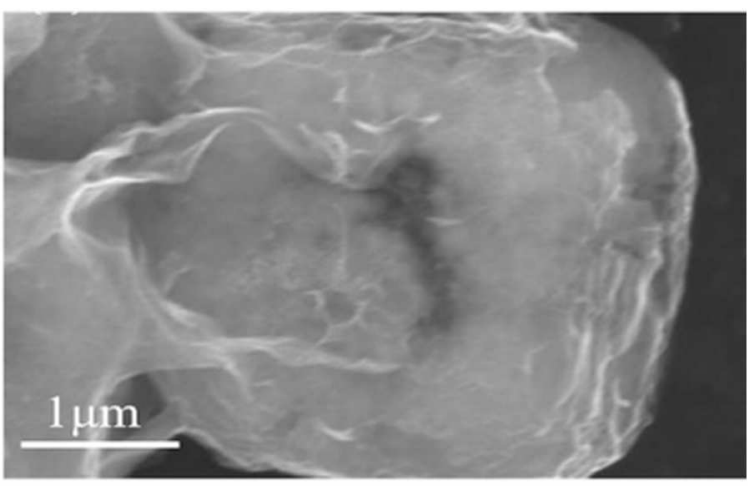

D

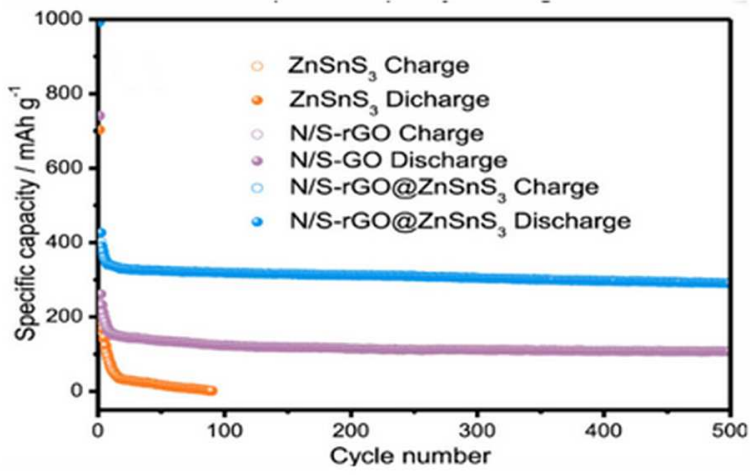

$\mathbf{E}$

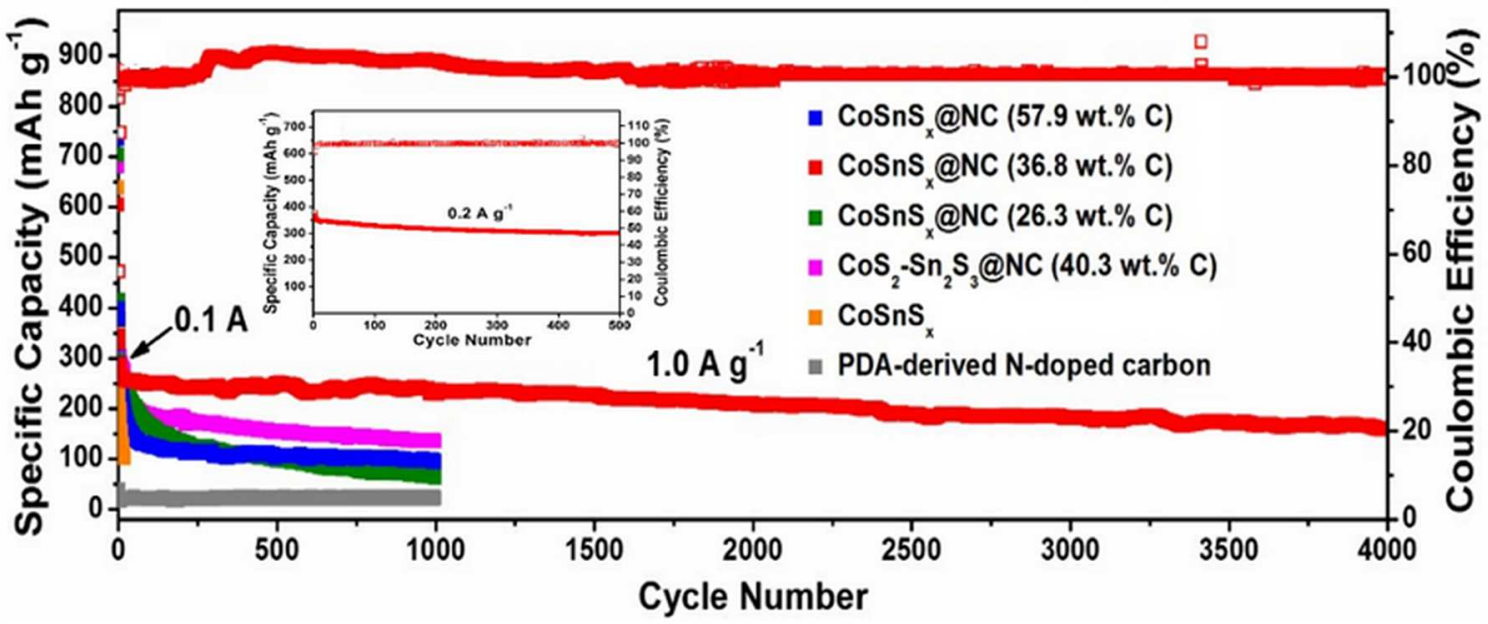

FIGURE 7 | (A,B) FESEM images of ZnSnS 3 and N/S-rGO@ZnSnS 3 , (C,D) Rate and cycling performance of N/S-rGO, ZnSnS 3 , and N/S-rGO@ZnSnS 3 electrodes. Reproduced with permission from Liu et al. (2019) Copyright 2019. Elsevier. (E) Long-term stability of amorphous CoSnS $@$ @N nanoboxes with various carbon content, amorphous CoSnS $\mathrm{x}_{\mathrm{x}}$ nanoboxes, crystalline CoS-Sn $\mathrm{S}_{3} @ \mathrm{NC}$ nanoboxes and PDA-derived $\mathrm{N}$-doped carbon at 1.0 A g ${ }^{-1}$. The inset in (E) shows the cycling performance and coulombic efficiency of the CoSnS $@$ @NC nanoboxes electrode at 0.2 $\mathrm{A} \mathrm{g}^{-1}$. Reproduced with permission from Liu et al. (2017) Copyright 2017. Royal Society of Chemistry.

rate capability $(752.3,604.7,570.1,546.9,519.7$, and $488.7 \mathrm{mAh}$ $\mathrm{g}^{-1}$ at $0.1,0.5,1.0,2.0,5.0$, and $10.0 \mathrm{~A} \mathrm{~g} \mathrm{~g}^{-1}$, respectively). Benefitting from these advantages (huge specific surface area, abundant active sites, and strong electrical conductivity) of carbon materials, the resulting composite electrode displayed an impressive electrochemical performance (Ou et al., 2019). Yang et al. reported a novel material consisted of $(\mathrm{SnCo}) \mathrm{S}_{2}$ nanocubes interlaced with 2D sulfur-doped graphene (SG) nanosheets
((SnCo)S $\left.\mathrm{S}_{2} / \mathrm{SG}\right)$ synthesized by a simple co-precipitation method and annealing. It exhibited an excellent reversible capacity of 487 mAh $\mathrm{g}^{-1}$ for 5,000 cycles at $5 \mathrm{~A} \mathrm{~g}^{-1}$ as well as a high capacity retention of $92.6 \%$ (Yang et al., 2019).

\section{Other BMSs}

In addition to the above-mentioned BMSs, Manthiram et al. have reported a nano-rod cluster $\mathrm{Bi}_{0.94} \mathrm{Sb}_{1.06} \mathrm{~S}_{3}$-graphite as 


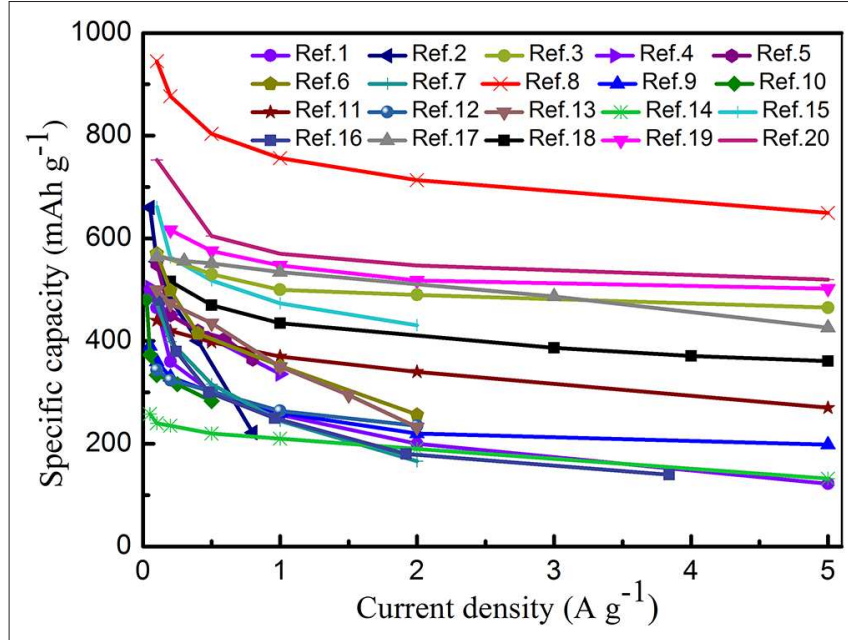

FIGURE 8 | Rate capability at various current densities from 0.1 to $5 \mathrm{~A} \mathrm{~g}^{-1}$ for different bimetallic sulfides in SIBs. Ref.1 (Choi and Kang, 2015a), Ref.2 (Chen J. et al., 2017), Ref.3 (Zhang et al., 2016), Ref.4 (Yang et al., 2019), Ref.5 (Lv et al., 2018), Ref.6 (Zhang et al., 2018), Ref.7 (Gong et al., 2018), Ref.8 (Huang et al., 2018), Ref.9 (Liu et al., 2017), Ref.10 (Liu et al., 2019), Ref.11 (Zhang K. et al., 2019), Ref.12 (Jia et al., 2018), Ref.13 (Cao et al., 2019), Ref.14 (Chen et al., 2019), Ref.15 (Ou et al., 2019), Ref.16 (Li Q. et al., 2019), Ref.17 (Kong et al., 2018), Ref.18 (Kim and Kang, 2017), Ref.19 (Zhao and Manthiram, 2015), Ref.20 (Krengel et al., 2017).

SIB anode material. They found that the design of solid solutions can be regarded as an ideal method to research new anode materials with excellent electrochemical performances for SIBs. The $\mathrm{Bi}_{0.94} \mathrm{Sb}_{1.06} \mathrm{~S}_{3}$-graphite anode displayed a remarkable capacity of $380 \mathrm{mAh} \mathrm{g}^{-1}$ after 200 cycles at $1 \mathrm{~A} \mathrm{~g} \mathrm{~g}^{-1}$, which is higher than the that of $\mathrm{Sb}_{2} \mathrm{~S}_{3}$-graphite electrode $(\sim 50$ $\left.\mathrm{mAh} \mathrm{g}^{-1}\right)$ and $\mathrm{Bi}_{2} \mathrm{~S}_{3}$-graphite electrode $\left(\sim 210 \mathrm{mAh} \mathrm{g}^{-1}\right)$. This means that bimetallic atoms can not only enhance the cycling stability of electrode materials, but also improve their capacity (Zhao and Manthiram, 2015). Zhong et al. successfully designed a novel yolk-shell hydrangea-like microflower composite self-assembled by nanosheets for SIBs. Accordingly, a high capacity of $607.14 \mathrm{mAh} \mathrm{g}^{-1}$ was delivered at $0.05 \mathrm{~A} \mathrm{~g}^{-1}$, along with reducing the volume expansion and enhancing the cycling stability to a great extent because of the unique structure of the electrode material (Zhong et al., 2019). Furthermore, the rate performance of different BMS materials is depicted in Figure 8, and a comparison between the cycle performances of BMSs and MSs is summarized in Table 4.

\section{CONCLUSIONS AND PERSPECTIVES}

In this review, the latest development of BMSs as anode materials for SIBs was systematically summarized. BMSs reveal obvious merits with relatively high electroconductivity and electrochemical activity. Moreover, the significant effect of selfmatrix and self-conductivity due to the reaction of two metal elements with $\mathrm{Na}$ can be totally effective. Indeed, due to the
TABLE 4 | Comparison between the electrochemical performance of BMS and MS anodes in SIBs.

\begin{tabular}{|c|c|c|c|c|}
\hline BMSs & MSs & $\begin{array}{l}\text { Current } \\
\text { density } \\
\left(\mathbf{A ~ g ~}^{-1}\right)\end{array}$ & $\begin{array}{c}\text { Cycle } \\
\text { number }\end{array}$ & $\begin{array}{c}\text { Specific } \\
\text { capacity } \\
\left(\mathrm{mAh} \mathrm{g}^{-1}\right)\end{array}$ \\
\hline & $\mathrm{CoS}_{2} / \mathrm{C}$ & 0.5 & 60 & 330 \\
\hline \multirow[t]{3}{*}{$\mathrm{NiCO}_{2} \mathrm{~S}_{4} @ \mathrm{NC}$} & & 6 & 5,000 & 395.6 \\
\hline & $\mathrm{NiS}_{2}$ & 0.5 & 1,000 & 319 \\
\hline & $\mathrm{FeS}_{2}$ & 1 & 400 & 180 \\
\hline \multirow[t]{3}{*}{$\mathrm{Co}_{0.5} \mathrm{Fe}_{0.5} \mathrm{~S}_{2}$} & & 2 & 5,000 & 220 \\
\hline & $\mathrm{Co}_{9} \mathrm{~S}_{8}$ & 1 & 70 & 266 \\
\hline & $\mathrm{SnS}_{2}-\mathrm{rGO}$ & 1 & 400 & 500 \\
\hline \multirow[t]{3}{*}{$(\mathrm{SnCo}) \mathrm{S}_{2} / \mathrm{SG}$} & & 5 & 5,000 & 487 \\
\hline & - & - & - & - \\
\hline & $\mathrm{Cog}_{8} / \mathrm{NC}$ & 0.05 & 100 & 274.7 \\
\hline \multirow[t]{3}{*}{$\left(\mathrm{CO}_{0.5} \mathrm{Ni}_{0.5}\right)_{9} \mathrm{~S}_{8} / \mathrm{NC}$} & & & & 723.7 \\
\hline & $\mathrm{Ni}_{3} \mathrm{~S}_{2} / \mathrm{NC}$ & & & 601.7 \\
\hline & $\mathrm{SnS}_{2} / \mathrm{C}$ & 5 & 500 & 235 \\
\hline \multirow[t]{3}{*}{$\mathrm{SnS}_{2} / \mathrm{Mn}_{2} \mathrm{SnS}_{4} / \mathrm{C}$} & & & & 522.5 \\
\hline & - & - & - & - \\
\hline & $\mathrm{MoS}_{2}-\mathrm{rGO}$ & 1 & 200 & 209 \\
\hline \multirow[t]{3}{*}{$\mathrm{VMo}_{2} \mathrm{~S}_{4}-\mathrm{rGO}$} & & & & 254 \\
\hline & - & - & - & - \\
\hline & $\mathrm{MoS}_{2} / \mathrm{CTs}$ & 0.48 & 500 & 135 \\
\hline \multirow[t]{3}{*}{$\mathrm{NiMo}_{3} \mathrm{~S}_{4} / \mathrm{CTS}$} & & & 1,000 & 302 \\
\hline & $\mathrm{NiS}_{x} / \mathrm{CTS}$ & & 500 & 61 \\
\hline & FeS & 1 & 80 & 351 \\
\hline \multirow[t]{3}{*}{$\left(\mathrm{Fe}_{0.5} \mathrm{Ni}_{0.5}\right)_{9} \mathrm{~S}_{8}$} & & & & 601 \\
\hline & $\mathrm{NiS}$ & & & 293 \\
\hline & $\mathrm{Sb}_{2} \mathrm{~S}_{3}-\mathrm{G}$ & 1 & 200 & 80 \\
\hline \multirow[t]{2}{*}{$\mathrm{Bi}_{0.94} \mathrm{Sb}_{1.06} \mathrm{~S}_{3}-\mathrm{G}$} & & & & 380 \\
\hline & $\mathrm{Bi}_{2} \mathrm{~S}_{3}-\mathrm{G}$ & & & 220 \\
\hline
\end{tabular}

existence of "synergistic effect," the non-reacted part can serve as a provisional snubber/conductor for the reacted one owing to their different redox potential (Pumera et al., 2014; Wang et al., 2014; Chang et al., 2016; Liu et al., 2019). In this review, firstly, the synthesis strategies of BMSs have been introduced. Then, Na-storage mechanisms of various BMSs during the charge-discharge process has been discussed. More importantly, BMSs application as SIB anodes has been systematically analyzed, while putting forward insightful anticipations on its future development.

To avoid capacity fading of the BMS anode materials, the first strategy is designing novel nanostructures with suitable void space to alleviate the influence of volume expansion and contraction during the reaction process (Palomares et al., 2012; Slater et al., 2013; Ou et al., 2016; Putungan et al., 2016; Shen et al., 2016; Su et al., 2016). As the second strategy, integration with other electrochemically stable materials can not only restrain the volume expansion, but also advance the overall electroconductivity of the anode. Additionally, the dissolution of polysulfides in electrolyte during the electrochemical process 
can be suppressed to some extent (Wang et al., 2018). Up to now, plenty of reported BMS anode in SIBs refer to their combination with carbon-based materials. Thus, it is important for the development of SIBs anode materials to fully study the merits of nanostructured materials ( $\mathrm{Lu}$ et al., 2017; Ma et al., 2018). In the future, much more efforts need to be made to overcome the disadvantage of poor long-term cycling. It is expected that exploitation of rational-designed structures in BMSs can effectively improve the electrochemical performance in SIBs (Kim et al., 2012; Jiang et al., 2014; Su et al., 2015; Gao et al., 2017; Hwang et al., 2017).

Despite the all novel work has been done thus far, still more time, and efforts should be dedicated to effectively boost the electrochemical properties of BMSs to pave the way of their practical application in SIBs in the near future.

\section{REFERENCES}

Cao, D., Kang, W., Wang, S., Wang, Y., Sun, K., Yang, L., et al. (2019). In situ Ndoped carbon modified $\left(\mathrm{Co}_{0.5} \mathrm{Ni}_{0.5}\right)_{9} \mathrm{~S}_{8}$ solid-solution hollow spheres as highcapacity anodes for sodium-ion batteries. J. Mater. Chem. A 7, 8268-8276. doi: 10.1039/C9TA00709A

Cao, X., Tan, C., Sindoro, M., and Zhang, H. (2017). Hybrid micro/nano-structures derived from metal-organic frameworks: preparation and applications in energy storage and conversion. Chem. Soc. Rev. 46, 2660-2677. doi: 10.1039/C6CS00426A

Chang, K., Hai, X., and Ye, J. (2016). Transition metal disulfides as noble-metalalternative co-catalysts for solar hydrogen production. Adv. Energy Mater. 6:1502555. doi: 10.1002/aenm.201502555

Chang, L., Wang, K., Huang, L-A., He, Z., Zhu, S., Chen, M., et al. (2017). Hierarchical $\mathrm{CoO}$ microflower film with excellent electrochemical lithium/sodium storage performance. J. Mater. Chem. A 5, 20892-20902. doi: 10.1039/C7TA05027E

Che, H., Chen, S., Xie, Y., Wang, H., Amine, K., Liao, X-Z., et al. (2017). Electrolyte design strategies and research progress for room-temperature sodium-ion batteries. Energy Environ. Sci. 10, 1075-1101. doi: 10.1039/C7EE00524E

Chen, J., Li, S., Kumar, V., and Lee, P. S. (2017). Carbon coated bimetallic sulfide hollow nanocubes as advanced sodium ion battery anode. Adv. Energy Mater. 7:1700180. doi: 10.1002/aenm.201700180

Chen, J., Mohrhusen, L., Ali, G., Li, S., Chung, K. Y., Al-Shamery, K., et al. (2019). Electrochemical mechanism investigation of $\mathrm{Cu}_{2} \mathrm{MoS}_{4}$ hollow nanospheres for fast and stable sodium ion storage. Adv. Funct. Mater. 29:1807753. doi: 10.1002/adfm.201807753

Chen, S., Wu, C., Shen, L., Zhu, C., Huang, Y., Xi, K., et al. (2017). Challenges and perspectives for NASICON-Type electrode materials for advanced sodium-ion batteries. Adv. Mater. 29:1700431. doi: 10.1002/adma.2017 00431

Chen, T., Cheng, B., Chen, R., Hu, Y., Lv, H., Zhu, G., et al. (2016). Hierarchical ternary carbide nanoparticle/carbon nanotube-inserted $\mathrm{N}$ doped carbon concave-polyhedrons for efficient lithium and sodium storage. ACS Appl. Mater. Interfaces 8, 26834-26841. doi: 10.1021/acsami.6b 08911

Chen, Y., Yu, X., Li, Z., Paik, U., and Lou, X. D. (2016). Hierarchical $\mathrm{MoS}_{2}$ tubular structures internally wired by carbon nanotubes as a highly stable anode material for lithium-ion batteries. Sci. Adv. 2:e1600021. doi: 10.1126/sciadv.1600021

Chen, Z., Wu, R., Liu, M., Wang, H., Xu, H., Guo, Y., et al. (2017). General synthesis of dual carbon-confined metal sulfides quantum dots toward highperformance anodes for sodium-ion batteries. Adv. Funct. Mater. 27:1702046. doi: 10.1002/adfm.201702046

Cho, E., Song, K., Park, M. H., Nam, K. W., and Kang, Y. M. (2016). SnS 3D flowers with superb kinetic properties for anodic use in next-generation sodium rechargeable batteries. Small 12, 2510-2517. doi: 10.1002/smll.201503168

\section{AUTHOR CONTRIBUTIONS}

$\mathrm{YH}, \mathrm{DX}$, and XL contributed to the conception and design of the study. YH organized the database, performed the statistical analysis, and wrote the manuscript with the help of HM, JP, YiL, YuL, DL, QS, and XS. All authors have given approval to the final version of the manuscript.

\section{ACKNOWLEDGMENTS}

The authors sincerely appreciate the support from Natural Science Foundation of Qinghai Province of China (2020ZJ-910), the National Natural Science Foundation of China (51672189), and Tianjin Science and Technology Project (18PTZWHZ00020).

Choi, S. H., and Kang, Y. C. (2015a). Synergetic compositional and morphological effects for improved $\mathrm{Na}^{+}$storage properties of $\mathrm{Ni}_{3} \mathrm{Co}_{6} \mathrm{~S}_{8}$-reduced graphene oxide composite powders. Nanoscale 7, 6230-6237. doi: 10.1039/C5NR00012B

Choi, S. H., and Kang, Y. C. (2015b). Synergetic effect of yolk-shell structure and uniform mixing of $\mathrm{SnS}-\mathrm{MoS}_{2}$ nanocrystals for improved na-ion storage capabilities. ACS Appl. Mater. Interfaces 7, 24694-24702. doi: 10.1021/acsami.5b07093

Choi, S. H., Ko, Y. N., Lee, J-K., and Kang, Y. C. (2015). 3D MoS graphene microspheres consisting of multiple nanospheres with superior sodium ion storage properties. Adv. Funct. Mater. 25, 1780-1788. doi: $10.1002 /$ adfm. 201402428

Deng, P., Yang, J., He, W., Li, S., Zhou, W., Tang, D., et al. (2018). Tin-assisted $\mathrm{Sb}_{2} \mathrm{~S}_{3}$ nanoparticles uniformly grafted on graphene effectively improves sodium-ion storage performance. ChemElectroChem 5, 811-816. doi: 10.1002/celc.201800016

Dong, S., Li, C., Ge, X., Li, Z., Miao, X., and Yin, L. (2017). ZnS-Sb $\mathrm{S}_{3} @ \mathrm{C}$ coredouble shell polyhedron structure derived from metal-organic framework as anodes for high performance sodium ion batteries. ACS Nano 11, 6474-6482. doi: 10.1021/acsnano.7b03321

Du, Y., Zhu, X., Zhou, X., Hu, L., Dai, Z., and Bao, J. (2015). $\mathrm{Co}_{3} \mathrm{~S}_{4}$ porous nanosheets embedded in graphene sheets as high-performance anode materials for lithium and sodium storage. J. Mater. Chem. A 3, 6787-6791. doi: 10.1039/C5TA00621J

Duan, J., Tang, X., Dai, H., Yang, Y., Wu, W., Wei, X., et al. (2019). Building safe lithium-ion batteries for electric vehicles: a review. Electrochem. Energy Rev. 3, 1-42. doi: 10.1007/s41918-019-00060-4

Fan, L., and Li, X. (2018). Recent advances in effective protection of sodium metal anode. Nano Energy 53, 630-642. doi: 10.1016/j.nanoen.2018.09.017

Fan, L., Li, X., Yan, B., Feng, J., Xiong, D., Li, D., et al. (2016). Controlled $\mathrm{SnO}_{2}$ crystallinity effectively dominating sodium storage performance. Adv. Energy Mater. 6:1502057. doi: 10.1002/aenm.201502057

Fang, G., Wu, Z., Zhou, J., Zhu, C., Cao, X., Lin, T., et al. (2018). Observation of pseudocapacitive effect and fast ion diffusion in bimetallic sulfides as an advanced sodium-ion battery anode. Adv. Energy Mater. 8:1703155. doi: 10.1002/aenm.201703155

Fang, Y., Xiao, L., Chen, Z., Ai, X., Cao, Y., and Yang, H. (2018). Recent advances in sodium-ion battery materials. Electrochem. Energy. Rev. 1, 294-323. doi: 10.1007/s41918-018-0008-X

Fu, Y., Zhang, Z., Yang, X., Gan, Y., and Chen, W. (2015). ZnS nanoparticles embedded in porous carbon matrices as anode materials for lithium ion batteries. RSC Adv. 5, 86941-86944. doi: 10.1039/C5RA15108B

Gao, X., Wang, J., Zhang, D., Adair, K., Feng, K., Sun, N., et al. (2017). Carbon coated bimetallic sulfide nanodots/carbon nanorod heterostructure enabling long-life lithium-ion batteries. J. Mater. Chem. A 5, 25625-25631. doi: 10.1039/C7TA06849B

Ge, X., Li, Z., and Yin, L. (2017). Metal-organic frameworks derived porous core/shellCoP@C polyhedrons anchored on 3D reduced graphene oxide 
networks as anode for sodium-ion battery. Nano Energy 32, 117-124. doi: 10.1016/j.nanoen.2016.11.055

Gong, Y., Zhao, J., Wang, H., and $\mathrm{Xu}$, J. (2018). $\mathrm{CuCo}_{2} \mathrm{~S}_{4} /$ reduced graphene oxide nanocomposites synthesized by one-step solvothermal method as anode materials for sodium ion batteries. Electrochim. Acta 292, 895-902. doi: 10.1016/j.electacta.2018.09.194

Huang, Y., Xie, M., Wang, Z., Jiang, Y., Xiao, G., Li, S., et al. (2018). Fast sodium storage kinetics of lantern-like $\mathrm{Ti}_{0.25} \mathrm{Sn}_{0.75} \mathrm{~S}_{2}$ connected via carbon nanotubes. Energy Storage Mater. 11, 100-111. doi: 10.1016/j.ensm.2017.10.004

Hwang, J. Y., Myung, S. T., and Sun, Y. K. (2017). Sodium-ion batteries: present and future. Chem. Soc. Rev. 46, 3529-3614. doi: 10.1039/C6CS00776G

Jia, H., Dirican, M., Sun, N., Chen, C., Yan, C., Zhu, P., et al. (2018). Advanced $\mathrm{ZnSnS}_{3} @ \mathrm{rGO}$ anode material for superior sodium-ion and lithiumion storage with ultralong cycle life. ChemElectroChem 6, 1183-1191. doi: 10.1002/celc.201801333

Jiang, Y., Hu, M., Zhang, D., Yuan, T., Sun, W., Xu, B., et al. (2014). Transition metal oxides for high performance sodium ion battery anodes. Nano Energy 5, 60-66. doi: 10.1016/j.nanoen.2014.02.002

Jin, R., Liu, D., Liu, C., and Liu, G. (2015). Hierarchical $\mathrm{NiCo}_{2} \mathrm{~S}_{4}$ hollow spheres as a high performance anode for lithium ion batteries. RSC Adv. 5, 84711-84717. doi: $10.1039 /$ C5RA14412D

Kang, W., Wang, Y., and Xu, J. (2017). Recent progress in layered metal dichalcogenide nanostructures as electrodes for high-performance sodium-ion batteries. J. Mater. Chem. A 5, 7667-7690. doi: 10.1039/C7TA00003K

Kim, H., Lim, E., Jo, C., Yoon, G., Hwang, J., Jeong, S., et al. (2015). Orderedmesoporous $\mathrm{Nb}_{2} \mathrm{O}_{5}$ /carbon composite as a sodium insertion material. Nano Energy 16, 62-70. doi: 10.1016/j.nanoen.2015.05.015

Kim, J. H., and Kang, Y. C. (2017). Yolk-shell-structured $\left(\mathrm{Fe}_{0.5} \mathrm{Ni}_{0.5}\right)_{9} \mathrm{~S}_{8}$ solidsolution powders: synthesis and application as anode materials for $\mathrm{Na}$-ion batteries. Nano Res. 10, 3178-3188. doi: 10.1007/s12274-017-1535-1

Kim, S-W., Seo, D-H., Ma, X., Ceder, G., and Kang, K. (2012). Electrode materials for rechargeable sodium-ion batteries: potential alternatives to current lithiumion batteries. Adv. Energy Mater. 2, 710-721. doi: 10.1002/aenm.201200026

Kong, D., Wang, Y., Lim, Y. V., Huang, S., Zhang, J., Liu, B., et al. (2018). 3D hierarchical defect-rich $\mathrm{NiMo}_{3} \mathrm{~S}_{4}$ nanosheet arrays grown on carbon textiles for high-performance sodium-ion batteries and hydrogen evolution reaction. Nano Energy 49, 460-470. doi: 10.1016/j.nanoen.2018.04.051

Kong, S., Jin, Z., Liu, H., and Wang, Y. (2014). Morphological effect of graphene nanosheets on ultrathin $\operatorname{CoS}$ nanosheets and their applications for highperformance Li-ion batteries and photocatalysis. J. Phys. Chem. C 118, 25355-25364. doi: 10.1021/jp508698q

Krengel, M., Hansen, A. L., Kaus, M., Indris, S., Wolff, N., Kienle, L., et al. (2017). $\mathrm{CuV}_{2} \mathrm{~S}_{4}$ : a high rate capacity and stable anode material for sodium ion batteries. ACS Appl. Mater. Interfaces 9, 21283-21291. doi: 10.1021/acsami.7b04739

Kundu, D., Talaie, E., Duffort, V., and Nazar, L. F. (2015). The emerging chemistry of sodium ion batteries for electrochemical energy storage. Angew. Chem. Int. Ed. Engl. 54, 3431-3448. doi: 10.1002/anie.201410376

Lai, C-H., Lu, M-Y., and Chen, L-J. (2012). Metal sulfide nanostructures: synthesis, properties and applications in energy conversion and storage. J. Mater. Chem. 22, 19-30. doi: 10.1039/C1JM13879K

Li, L., Peng, S., Wu, H. B., Yu, L., Madhavi, S., and Lou, X. W. D. (2015). A flexible quasi-solid-state asymmetric electrochemical capacitor based on hierarchical porous $\mathrm{V}_{2} \mathrm{O}_{5}$ nanosheets on carbon nanofibers. Adv. Energy Mater. 5:1500753. doi: 10.1002/aenm.201500753

Li, Q., Jiao, Q., Feng, X., Zhao, Y., Li, H., Feng, C., et al. (2019). One-pot synthesis of $\mathrm{CuCo}_{2} \mathrm{~S}_{4}$ sub-microspheres for high-performance lithium-/sodium-ion batteries. ChemElectroChem 6, 1558-1566. doi: 10.1002/celc.201900079

Li, S., Ge, P., Jiang, F., Shuai, H., Xu, W., Jiang, Y., et al. (2019). The advance of nickel-cobalt-sulfide as ultra-fast/high sodium storage materials: the influences of morphology structure, phase evolution and interface property. Energy Storage Mater. 16, 267-280. doi: 10.1016/j.ensm.2018.06.006

Li, X., Hu, Y., Liu, J., Lushington, A., Li, R., and Sun, X. (2013). Structurally tailored graphene nanosheets as lithium ion battery anodes: an insight to yield exceptionally high lithium storage performance. Nanoscale 5, 12607-12615. doi: $10.1039 / \mathrm{c} 3 \mathrm{nr} 04823 \mathrm{c}$

Li, X., and Wang, C. (2012). Significantly increased cycling performance of novel "self-matrix" $\mathrm{NiSnO}_{3}$ anode in lithium ion battery application. RSC Adv. 2, 6150-6154. doi: 10.1039/c2ra20527k
Li, Y., Hu, Y-S., Qi, X., Rong, X., Li, H., Huang, X., et al. (2016). Advanced sodium-ion batteries using superior low cost pyrolyzed anthracite anode: towards practical applications. Energy Storage Mater. 5, 191-197. doi: 10.1016/j.ensm.2016.07.006

Li, Y., Zheng, Y., Yao, J., Xiao, J., Yang, J., and Xiao, S. (2017). Facile synthesis of nanocrystalline-assembled nest-like $\mathrm{NiO}$ hollow microspheres with superior lithium storage performance. RSC Adv. 7, 31287-31297. doi: 10.1039/C7RA05373H

Li, Z., Zhang, L., Ge, X., Li, C., Dong, S., Wang, C., et al. (2017). Core-shell structured $\mathrm{CoP} / \mathrm{FeP}$ porous microcubes interconnected by reduced graphene oxide as high performance anodes for sodium ion batteries. Nano Energy 32, 494-502. doi: 10.1016/j.nanoen.2017.01.009

Lin, Y., Qiu, Z., Li, D., Ullah, S., Hai, Y., Xin, H., et al. (2018). NiS $2 @ \mathrm{CoS}_{2}$ nanocrystals encapsulated in $\mathrm{N}$-doped carbon nanocubes for high performance lithium/sodium ion batteries. Energy Storage Mater. 11, 67-74. doi: 10.1016/j.ensm.2017.06.001

Liu, X., Hao, Y., Shu, J., Sari, H. M. K., Lin, L., Kou, H., et al. (2019). Nitrogen/sulfur dual-doping of reduced graphene oxide harvesting hollow $\mathrm{ZnSnS}_{3}$ nano-microcubes with superior sodium storage. Nano Energy 57, 414-423. doi: 10.1016/j.nanoen.2018.12.024

Liu, X., Wang, Y., Wang, Z., Zhou, T., Yu, M., Xiu, L., et al. (2017). Achieving ultralong life sodium storage in amorphous cobalt-tin binary sulfide nanoboxes sheathed in N-doped carbon. J. Mater. Chem. A 5, 10398-10405. doi: 10.1039/C7TA01701D

Lu, H., Chen, R., Hu, Y., Wang, X., Wang, Y., Ma, L., et al. (2017). Bottom-up synthesis of nitrogen-doped porous carbon scaffolds for lithium and sodium storage. Nanoscale 9, 1972-1977. doi: 10.1039/C6NR08296C

Lu, Y., Zhao, Q., Zhang, N., Lei, K., Li, F., and Chen, J. (2016). Facile spraying synthesis and high-performance sodium storage of mesoporous $\mathrm{MoS}_{2} / \mathrm{C}$ microspheres. Adv. Funct. Mater. 26, 911-918. doi: 10.1002/adfm.201504062

Lv, J., Bai, D., Yang, L., Guo, Y., Yan, H., and Xu, S. (2018). Bimetallic sulfide nanoparticles confined by dual-carbon nanostructures as anodes for lithium-/sodium-ion batteries. Chem. Commun. 54, 8909-8912. doi: 10.1039/C8CC04318C

Ma, L., Chen, R., Hu, Y., Zhu, G., Chen, T., Lu, H., et al. (2016). Hierarchical porous nitrogen-rich carbon nanospheres with high and durable capabilities for lithium and sodium storage. Nanoscale 8, 17911-17918. doi: 10.1039/C6NR06307A

Ma, L., Gao, X., Zhang, W., Yuan, H., Hu, Y., Zhu, G., et al. (2018). Ultrahigh rate capability and ultralong cycling stability of sodium-ion batteries enabled by wrinkled black titania nanosheets with abundant oxygen vacancies. Nano Energy 53, 91-96. doi: 10.1016/j.nanoen.2018.08.043

Maleki Kheimeh Sari, H., and Li, X. (2019). Controllable cathode-electrolyte interface of $\mathrm{Li}\left[\mathrm{Ni}_{0.8} \mathrm{Co}_{0.1} \mathrm{Mn}_{0.1}\right] \mathrm{O}_{2}$ for lithium ion batteries: a review. $A d v$. Energy Mater. 9:1901597. doi: 10.1002/aenm.201901597

Meng, X. (2017). Atomic-scale surface modifications and novel electrode designs for high-performance sodium-ion batteries via atomic layer deposition. J. Mater. Chem. A 5, 10127-10149. doi: 10.1039/C7TA0 $2742 \mathrm{G}$

Ortiz-Vitoriano, N., Drewett, N. E., Gonzalo, E., and Rojo, T. (2017). High performance manganese-based layered oxide cathodes: overcoming the challenges of sodium ion batteries. Energy Environ. Sci. 10, 1051-1074. doi: 10.1039/C7EE00566K

Ou, X., Cao, L., Liang, X., Zheng, F., Zheng, H. S., Yang, X., et al. (2019). Fabrication of $\mathrm{SnS}_{2} / \mathrm{Mn}_{2} \mathrm{SnS}_{4} /$ carbon heterostructures for sodium-ion batteries with high initial coulombic efficiency and cycling stability. ACS Nano 13, 3666-3676. doi: 10.1021/acsnano.9b00375

Ou, X., Xiong, X., Zheng, F., Yang, C., Lin, Z., Hu, R., et al. (2016). In situ X-ray diffraction characterization of $\mathrm{NbS}_{2}$ nanosheets as the anode material for sodium ion batteries. J. Power Sources 325, 410-416. doi: 10.1016/j.jpowsour.2016.06.055

Palomares, V., Serras, P., Villaluenga, I., Hueso, K. B., Carretero-González, J., and Rojo, T. (2012). Na-ion batteries, recent advances and present challenges to become low cost energy storage systems. Energy Environ. Sci. 5:5884-5901. doi: $10.1039 /$ c2ee02781j

Pumera, M., Sofer, Z., and Ambrosi, A. (2014). Layered transition metal dichalcogenides for electrochemical energy generation and storage. J. Mater. Chem. A 2, 8981-8987. doi: 10.1039/C4TA00652F 
Putungan, D. B., Lin, S. H., and Kuo, J. L. (2016). Metallic VS 2 monolayer polytypes as potential sodium-ion battery anode via ab initio random structure searching. ACS Appl. Mater. Interfaces 8, 18754-18762. doi: 10.1021/acsami.6b03499

Qin, W., Chen, T., Lu, T., Chua, D. H. C., and Pan, L. (2016a). Layered nickel sulfide-reduced graphene oxide composites synthesized via microwave-assisted method as high performance anode materials of sodium-ion batteries. J. Power Sources 302, 202-209. doi: 10.1016/j.jpowsour.2015.10.064

Qin, W., Li, D., Zhang, X., Yan, D., Hu, B., and Pan, L. (2016b). ZnS nanoparticles embedded in reduced graphene oxide as high performance anode material of sodium-ion batteries. Electrochim. Acta 191, 435-443. doi: 10.1016/j.electacta.2016.01.116

Qu, B., Ma, C., Ji, G., Xu, C., Xu, J., Meng, Y. S., et al. (2014). Layered $\mathrm{SnS}_{2}$-reduced graphene oxide composite-a high-capacity, high-rate, and longcycle life sodium-ion battery anode material. Adv. Mater. 26, 3854-3859. doi: 10.1002/adma.201306314

Shen, F., Luo, W., Dai, J., Yao, Y., Zhu, M., Hitz, E., et al. (2016). Ultra-thick, lowtortuosity, and mesoporous wood carbon anode for high-performance sodiumion batteries. Adv. Energy Mater. 6:1600377. doi: 10.1002/aenm.201600377

Slater, M. D., Kim, D., Lee, E., and Johnson, C. S. (2013). Sodium-ion batteries. Adv. Funct. Mater. 23, 947-958. doi: 10.1002/adfm.201200691

Song, Y., Chen, Z., Li, Y., Wang, Q., Fang, F., Zhou, Y-N., et al. (2017). Pseudocapacitance-tuned high-rate and long-term cyclability of $\mathrm{NiCo}_{2} \mathrm{~S}_{4}$ hexagonal nanosheets prepared by vapor transformation for lithium storage. J. Mater. Chem. A 5, 9022-9031. doi: 10.1039/C7TA01758H

Stephenson, T., Li, Z., Olsen, B., and Mitlin, D. (2014). Lithium ion battery applications of molybdenum disulfide $\left(\mathrm{MoS}_{2}\right)$ nanocomposites. Energy Environ. Sci. 7, 209-231. doi: 10.1039/C3EE42591F

$\mathrm{Su}, \mathrm{D}$., Dou, S., and Wang, G. (2015). Ultrathin $\mathrm{MoS}_{2}$ nanosheets as anode materials for sodium-ion batteries with superior performance. Adv. Energy Mater. 5:1401205. doi: 10.1002/aenm.201401205

$\mathrm{Su}, \mathrm{H}$., Jaffer, S., and Yu, H. (2016). Transition metal oxides for sodium-ion batteries. Energy Storage Mater. 5, 116-131. doi: 10.1016/j.ensm.2016.06.005

Su, Z., Liu, J., Li, M., Zhu, Y., Qian, S., Weng, M., et al. (2020). Defect engineering in titanium-based oxides for electrochemical energy storage devices. Electrochem. Energy Rev 3, 90-147. doi: 10.1007/s41918-020-00064-5

Tang, Q., Cui, Y., Wu, J., Qu, D., Baker, A. P., Ma, Y., et al. (2017). Ternary tin selenium sulfide $\left(\mathrm{SnSe}_{0.5} \mathrm{~S}_{0.5}\right)$ nano alloy as the high-performance anode for lithium-ion and sodium-ion batteries. Nano Energy 41, 377-386. doi: $10.1016 /$ j.nanoen.2017.09.052

Wang, H., Feng, H., and Li, J. (2014). Graphene and graphene-like layered transition metal dichalcogenides in energy conversion and storage. Small 10, 2165-2181. doi: 10.1002/smll.201303711

Wang, T., Su, D., Shanmukaraj, D., Rojo, T., Armand, M., and Wang, G. (2018). Electrode materials for sodium-ion batteries: considerations on crystal structures and sodium storage mechanisms. Electrochem. Energy Rev. 1, 200-237. doi: 10.1007/s41918-018-0009-9

Wen, Y., Peng, S., Wang, Z., Hao, J., Qin, T., Lu, S., et al. (2017). Facile synthesis of ultrathin $\mathrm{NiCo}_{2} \mathrm{~S}_{4}$ nano-petals inspired by blooming buds for high-performance supercapacitors. J. Mater. Chem. A 5, 7144-7152. doi: $10.1039 /$ C7TA01326D

Wu, X., Li, S., Wang, B., Liu, J., and Yu, M. (2016). $\mathrm{NiCo}_{2} \mathrm{~S}_{4}$ nanotube arrays grown on flexible nitrogen-doped carbon foams as three-dimensional binderfree integrated anodes for high-performance lithium-ion batteries. Phys. Chem. Chem. Phys. 18, 4505-4512. doi: 10.1039/C5CP07541F

Xia, X., Zhu, C., Luo, J., Zeng, Z., Guan, C., Ng, C. F., et al. (2014). Synthesis of free-standing metal sulfide nanoarrays via anion exchange reaction and their electrochemical energy storage application. Small 10, 766-773. doi: $10.1002 / \mathrm{smll} .201302224$

Xiao, J., Wan, L., Yang, S., Xiao, F., and Wang, S. (2014). Design hierarchical electrodes with highly conductive $\mathrm{NiCo}_{2} \mathrm{~S}_{4}$ nanotube arrays grown on carbon fiber paper for high-performance pseudocapacitors. Nano Lett. 14, 831-838. doi: $10.1021 / \mathrm{nl} 404199 \mathrm{v}$

Xiao, Y., Lee, S. H., and Sun, Y-K. (2017). The application of metal sulfides in sodium ion batteries. Adv. Energy Mater. 7:1601329. doi: 10.1002/aenm.201601329

Xiong, D., Li, X., Bai, Z., and Lu, S. (2018). Recent advances in layered $\mathrm{Ti}_{3} \mathrm{C}_{2} \mathrm{~T}_{\mathrm{x}}$ MXene for electrochemical energy storage. Small 14:e1703419. doi: $10.1002 /$ smll.201703419
Xu, X., Yu, D., Zhou, H., Zhang, L., Xiao, C., Guo, C., et al. (2016). MoS nanosheets grown on amorphous carbon nanotubes for enhanced sodium storage. J. Mater. Chem. A 4, 4375-4379. doi: 10.1039/C6TA00068A

Yan, B., Li, X., Bai, Z., Lin, L., Chen, G., Song, X., et al. (2017). Superior sodium storage of novel $\mathrm{VO}_{2}$ nano-microspheres encapsulated into crumpled reduced graphene oxide. J. Mater. Chem. A 5, 4850-4860. doi: 10.1039/C6TA10309J

Yan, Y., Yin, Y-X., Guo, Y-G., and Wan, L-J. (2014). A sandwich-like hierarchically porous carbon/graphene composite as a high-performance anode material for sodium-ion batteries. Adv. Energy Mater. 4:1301584. doi: 10.1002/aenm.201301584

Yang, C., Liang, X., Ou, X., Zhang, Q., Zheng, H-S., Zheng, F., et al. (2019). Heterostructured nanocube-shaped binary sulfide $(\mathrm{SnCo}) \mathrm{S}_{2}$ interlaced with S-doped graphene as a high-performance anode for advanced $\mathrm{Na}^{+}$batteries. Adv. Funct. Mater. 29:1807971. doi: 10.1002/adfm.2018 07971

Yang, J., Ma, M., Sun, C., Zhang, Y., Huang, W., and Dong, X. (2015). Hybrid $\mathrm{NiCo}_{2} \mathrm{~S}_{4} @ \mathrm{MnO}_{2}$ heterostructures for high-performance supercapacitor electrodes. J. Mater. Chem. A 3, 1258-1264. doi: 10.1039/C4TA0 $5747 \mathrm{C}$

Youn, D. H., Stauffer, S. K., Xiao, P., Park, H., Nam, Y., Dolocan, A., et al. (2016). Simple synthesis of nanocrystalline tin sulfide/ $\mathrm{N}$-doped reduced graphene oxide composites as lithium ion battery anodes. ACS Nano 10, 10778-10788. doi: 10.1021/acsnano.6b04214

Yu, D. J., Yuan, Y. F., Zhang, D., Yin, S. M., Lin, J. X., Rong, Z., et al. (2016). Nickel cobalt sulfide nanotube array on nickel foam as anode material for advanced lithium-ion batteries. Electrochim. Acta 198, 280-286. doi: 10.1016/j.electacta.2016.01.189

Yu, L., and Chen, G. Z. (2020). Supercapatteries as high-performance electrochemical energy storage devices. Electrochem. Energy Rev 3, 85-89. doi: 10.1007/s41918-020-00063-6

Yu, N., Zhu, M-Q., and Chen, D. (2015). Flexible all-solid-state asymmetric supercapacitors with three-dimensional $\mathrm{CoSe}_{2} /$ carbon cloth electrodes. J. Mater. Chem. A 3, 7910-7918. doi: 10.1039/C5TA0 0725A

Yu, X. Y., and David Lou, X. W. (2018). Mixed metal sulfides for electrochemical energy storage and conversion. Adv. Energy Mater. 8:1701592. doi: 10.1002/aenm.201701592

Yu, X-Y., Yu, L., and Lou, X. W. D. (2016). Metal sulfide hollow nanostructures for electrochemical energy storage. Adv. Energy Mater. 6:1501333. doi: 10.1002/aenm.201501333

Zhang, K., Park, M., Zhou, L., Lee, G. H., Shin, J., Hu, Z., et al. (2016). Cobaltdoped $\mathrm{FeS}_{2}$ nanospheres with complete solid solubility as a high-performance anode material for sodium-ion batteries. Angew. Chem. Int. Ed. Engl. 55, 12822-12826. doi: 10.1002/anie.201607469

Zhang, K., Sun, Y., Zhang, W., Guo, J., and Zhang, X. (2019). Interlayerexpanded $\mathrm{VMo}_{2} \mathrm{~S}_{4}$ nanosheets on RGO for high and fast lithium and sodium storage. J. Alloys Compd. 772, 178-185. doi: 10.1016/j.jallcom.2018. 09.082

Zhang, L., Wu, H. B., Yan, Y., Wang, X., and Lou, X. W. (2014). Hierarchical $\mathrm{MoS}_{2}$ microboxes constructed by nanosheets with enhanced electrochemical properties for lithium storage and water splitting. Energy Environ. Sci. 7, 3302-3306. doi: 10.1039/C4EE01932F

Zhang, Y., Wang, P., Yin, Y., Zhang, X., Fan, L., Zhang, N., et al. (2019). Heterostructured SnS-ZnS@C hollow nanoboxes embedded in graphene for high performance lithium and sodium ion batteries. Chem. Eng. J. 356, 1042-1051. doi: 10.1016/j.cej.2018.09.131

Zhang, Z., Li, Z., and Yin, L. (2018). Hollow prism $\mathrm{NiCo}_{2} \mathrm{~S}_{4}$ linked with interconnected reduced graphene oxide as a high performance anode material for sodium and lithium ion batteries. N. J. Chem. 42, 1467-1476. doi: $10.1039 / \mathrm{C} 7 \mathrm{NJ} 03581 \mathrm{~K}$

Zhao, Y., and Manthiram, A. (2015). $\mathrm{Bi}_{0.94} \mathrm{Sb}_{1.06} \mathrm{~S}_{3}$ nanorod cluster anodes for sodium-ion batteries: enhanced reversibility by the synergistic effect of the $\mathrm{Bi}_{2} \mathrm{~S}_{3}-\mathrm{Sb}_{2} \mathrm{~S}_{3}$ solid solution. Chem. Mater. 27, 6139-6145. doi: 10.1021 acs.chemmater.5b02833

Zheng, P., Dai, Z., Zhang, Y., Dinh, K. N., Zheng, Y., Fan, H., et al. (2017). Scalable synthesis of $\mathrm{SnS}_{2} / \mathrm{S}$-doped graphene composites for superior Li/Na-ion batteries. Nanoscale 9, 14820-14825. doi: 10.1039/C7NR0 $6044 \mathrm{~K}$ 
Zhong, J., Xiao, X., Zhang, Y., Zhang, N., Chen, M., Fan, X., et al. (2019). Rational design of Sn-Sb-S composite with yolk-shell hydrangea-like structure as advanced anode material for sodium-ion batteries. J. Alloys Compd. 793, 620-626. doi: 10.1016/j.jallcom.2019.04.232

Zhou, J., Qin, J., Guo, L., Zhao, N., Shi, C., and Liu, E. Z. (2016). Scalable synthesis of high-quality transition metal dichalcogenide nanosheets and their application as sodium-ion battery anodes. J. Mater. Chem. A 4, 17370-17380. doi: 10.1039/C6TA07425A

Zhou, Q., Liu, L., Huang, Z., Yi, L., Wang, X., and Cao, G. (2016). $\mathrm{Co}_{3} \mathrm{~S}_{4} @$ polyaniline nanotubes as high-performance anode materials for sodium ion batteries. J. Mater. Chem. A 4, 5505-5516. doi: 10.1039/C6TA01497F

Zhu, Y., Nie, P., Shen, L., Dong, S., Sheng, Q., Li, H., et al. (2015). High rate capability and superior cycle stability of a flower-like $\mathrm{Sb}_{2} \mathrm{~S}_{3}$ anode for high-capacity sodium ion batteries. Nanoscale 7, 3309-3315. doi: $10.1039 / \mathrm{C} 4 \mathrm{NR} 05242 \mathrm{~K}$

Conflict of Interest: The authors declare that the research was conducted in the absence of any commercial or financial relationships that could be construed as a potential conflict of interest.

Copyright (c) 2020 Huang, Xiong, Li, Maleki Kheimeh Sari, Peng, Li, Li, Li, Sun and Sun. This is an open-access article distributed under the terms of the Creative Commons Attribution License (CC BY). The use, distribution or reproduction in other forums is permitted, provided the original author(s) and the copyright owner(s) are credited and that the original publication in this journal is cited, in accordance with accepted academic practice. No use, distribution or reproduction is permitted which does not comply with these terms. 